\title{
A IMPORTÂNCIA DAS CUMARINAS PARA A QUÍMICA MEDICINAL E O DESENVOLVIMENTO DE COMPOSTOS BIOATIVOS NOS ÚLTIMOS ANOS
}

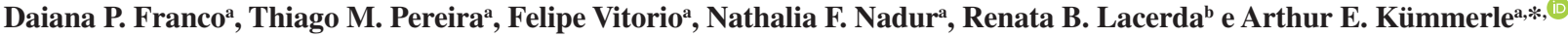 \\ aDepartamento de Química Orgânica, Instituto de Química, Universidade Federal Rural do Rio de Janeiro, 239897-000 Seropédica \\ - RJ, Brasil \\ 'Departamento de Ciências Farmacêuticas, Instituto de Ciências Biológicas e da Saúde, Universidade Federal Rural do Rio de \\ Janeiro, 239897-000 Seropédica - RJ, Brasil
}

Recebido em 10/06/2020; aceito em 02/09/2020; publicado na web em 15/10/2020

\begin{abstract}
THE IMPORTANCE OF CUMARINS FOR MEDICINAL CHEMISTRY AND THE DEVELOPMENT OF BIOACTIVE COMPOUNDS IN THE LAST YEARS. Coumarins are natural products characterized as $2 H$-chromen-2-one, according to IUPAC nomenclature, largely distributed in plants, as well as, in species of fungi and bacteria. Nowadays, many synthetic procedures allow the discovery of coumarins with expanded chemical space. The ability to exert non-covalent interactions with many enzymes and receptors in living organisms lead the coumarins to exhibit a wide range of biological activities and applications. Then, this manuscript provides an overview of the use of coumarin compounds in medicinal chemistry in treating many diseases. Important examples of the last years have been selected concerning the activities of coumarins as anticoagulant, anticancer, antioxidant, antiviral, antidiabetics, anti-inflammatory, antibacterial, antifungal, and anti-neurodegenerative agents. Thus, this work aims at contributing to the development of new rational research projects searching for new treatments and bioactive compounds for many pathologies using coumarin derivatives.
\end{abstract}

Keywords: coumarin; biological activity, structure-activity relationship, enzymes.

\section{INTRODUÇÃO}

As cumarinas são heterociclos orgânicos amplamente estudados e caracterizados como 1,2 benzopirona (1, Figura 1). Estruturalmente, consistem em um anel pirano fundido a benzeno com a carbonila da pirona na posição 2 (Figura 1) e são também denominadas como $2 \mathrm{H}$-cromen-2-onas. As mesmas, compreendem um grupo de produtos naturais encontrados na natureza e em uma grande variedade de plantas. ${ }^{1}$ A cumarina foi primeiramente isolada por Vogel em 1820 a partir da espécie dipteryx odorata, popularmente conhecida como cumaru. Após este primeiro relato, muitos trabalhos foram publicados demonstrando o isolamento e síntese de cumarinas e análogos a partir de outras espécies de plantas. $^{2}$

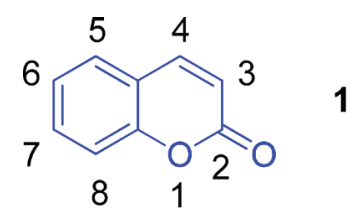

Figura 1. Estrutura química da cumarina

As cumarinas compreendem uma importante classe de metabólitos secundários amplamente distribuídos no reino vegetal, sendo encontradas em diversas partes de plantas, tanto em raízes como em flores e frutos. Diferentes espécies vegetais com hábitos bastante diversificados são capazes de biossintetizar cumarinas, como árvores, arbustos e ervas. ${ }^{3}$ Um número superior a 1300 cumarinas foram identificadas de fontes naturais, especialmente de plantas verdes. ${ }^{4}$ Porém, a biossíntese de cumarinas, cuja principal rota é a do ácido chiquímico, ${ }^{5}$ não está restrita apenas a plantas, pois algumas espécies de fungos (Armillariella tabescens, Fomitopsis officinalis)

*e-mail: akummerle@hotmail.com e bactérias (Streptomyces niveus, Escherichia coli) são capazes de biossintetizar cumarinas. ${ }^{\text {at-c }}$

As cumarinas possuem um importante efeito na fisiologia das plantas, atuando como antioxidante e inibidor enzimático. Essa classe de substâncias está envolvida no controle do crescimento das plantas, na respiração, fotossíntese e na defesa contra infecções. ${ }^{1}$ A variedade de propriedades biológicas reportada para as cumarinas contribuiu para o aumento do seu interesse no desenvolvimento da síntese orgânica, ${ }^{7}$ possibilitando a obtenção dos compostos conhecidos em maior escala e obtenção de novos derivados com aplicações biológicas e industriais.

A história da síntese de cumarinas começou em meados do século XIX com a descoberta da síntese de Perkin, ${ }^{8}$ seguida de outras metodologias clássicas para obtenção destes compostos como as reações de Pechmann e Knoevenagel. . $^{\text {a-b }}$

As cumarinas podem apresentar grande contribuição na pesquisa para prevenção e tratamento de doenças devido à capacidade de exercer interações não covalentes com estruturas proteicas, possuindo um amplo espectro de atividades biológicas. ${ }^{10}$ De fato as cumarinas têm sido amplamente investigadas como compostos bioativos ao longo dos anos. Como exemplo podemos destacar a varfarina (2), fármaco utilizado desde a década de 50 e, registrado pela ANVISA e FDA como agente anticoagulante para o tratamento e prevenção de doenças tromboembólicas. ${ }^{11 a-b}$

Além das bioatividades relacionadas às cumarinas, outra característica importante destes compostos explorada pela indústria são as propriedades luminescentes que estas apresentam, resultado das propriedades de transferência interna de carga do sistema conjugado $\pi-\pi^{*}$ rico em elétrons. Estes compostos possuem uma ampla gama de aplicações como: sondas de fluorescência, agentes de monitoramento de inibição enzimática ou fornecimento de informações farmacológicas em tempo real, ${ }^{12}$ corantes,,${ }^{9 a, 13}$ sensores de $\mathrm{pH}^{14}$ e potenciais agentes de biorreduçao. ${ }^{15 \mathrm{a}-\mathrm{b}}$

A grande variedade de aplicações para cumarinas reforça a importância da pesquisa e desenvolvimento de compostos análogos. 
Neste contexto, tendo como referência trabalhos científicos publicados na última década, este manuscrito tem como objetivo fornecer uma revisão da utilização de derivados cumarínicos em química medicinal como agentes anticoaguntes, antineurodegenerativos, anticancer, antioxidantes, antidiabéticos, antibacterianos, antifúngicos, antivirais e anti-inflamatórios.

\section{CUMARINAS ANTICOAGULANTES}

Entre todas as propriedades terapêuticas das cumarinas, uma das que mais se destacam é a sua aplicação como agentes anticoagulantes. ${ }^{16}$ Desde 1950, os derivados da 4-OH-cumarina, como a varfarina (2) e o dicumarol (3, Figura 2) têm sido amplamente utilizados como anticoagulantes orais, especialmente a varfarina (2), que é a cumarina mais utilizada no mundo devido à rápida e completa absorção no trato gastrointestinal. ${ }^{17,18}$

Estruturalmente, devido ao seu equilíbrio ceto-enólico, os derivados cumarínicos 4-hidroxilados assemelham-se à vitamina $\mathrm{K}$ (4), um elemento importante na produção de agentes coagulantes. ${ }^{16} \mathrm{~A}$ varfarina (2) na sua forma ceto (5) é considerada como um antagonista da vitamina $\mathrm{K}$ através da inibição da Vitamina K 2,3-Epoxídica Redutase (VKORC1), ${ }^{19,20}$ entretanto, devido ao estreito índice terapêutico e à hepatotoxicidade, os pesquisadores estão dedicando seus esforços para descobrir novos agentes anticoagulantes com ampla faixa terapêutica e menos efeitos adversos.

Nesse contexto, algumas alquil-4-hidroxicumarinas foram sintetizadas visando o metabolismo da vitamina $\mathrm{K} .{ }^{21}$ Com base na estrutura da varfarina, as principais modificações estruturais foram realizadas na posição C-3 da cumarina. A determinação in vitro da inibição da atividade VKORC1 em microssomos de fígado de rato forneceu constantes de inibição (Ki) variando de 20 a $3900 \mathrm{nM}$ para os compostos de 4-hidroxicumarina. Os compostos $6 \mathbf{a}(\mathrm{Ki}=20 \mathrm{nM})$ e $\mathbf{6 b}(\mathrm{Ki}=90 \mathrm{nM})$ foram selecionados como potenciais anticoagulantes ativos in vivo (10 $\mathrm{mg} \mathrm{kg}^{-1}$, administração oral) a curto prazo (24h). A melhor atividade foi observada para o composto $\mathbf{6 a}$, apresentando um tempo de protrombina 4 vezes maior após $24 \mathrm{~h}$ de sua administração (Figura 2). ${ }^{20}$

Antagonistas da vitamina K, heparinas e inibidores dependentes de antitrombina são as principais terapias anticoagulantes atuais. Apesar de seu uso mundial, existem alguns problemas associados a eles como o controle da atividade anticoagulante e efeitos adversos sobre o sangramento. ${ }^{22}$ Dessa forma, novos alvos com menores efeitos colaterais começaram a ser explorados e uma abordagem atraente é inibir o Fator Xa (FXa), diminuindo a produção de trombina sem diminuir os níveis necessários para a hemostasia primária. ${ }^{23}$

Exemplos de cumarina-3-carboxamidas foram descritos como inibidores de trombina e FXa. ${ }^{24,25}$ Mais recentemente, uma série de $\mathrm{N}$-cumarinil-6-amidinobenzamidas foi sintetizada e avaliada pela sua atividade antitrombótica in vivo. ${ }^{25}$ Três compostos apresentaram bons valores de tempo de protrombina (TP) in vivo $\left(0,4 \mathrm{mmol} \mathrm{kg}^{-1}\right.$ por 3 dias sucessivos): a amidina 7 (36,5 s), o oxadiazol 8 (42,3 s), o bis cumarinil-oxadiazol 9 (37,8 s) e o pirazol 10 (38,5 s); todos semelhantes à varfarina (42,3 s) na mesma dose (Figura 3). Além disso, estudos de docking utilizando o sítio ativo de FXa indicaram a inibição dessa enzima como possível mecanismo de ação. ${ }^{25}$

Em 2015 Lei e colaboradores descobriram novos compostos anticoagulantes naturais presentes em ervas medicinais chinesas, mais especificamente da espécie Ainsliaea fragrans. Foram identificados cinco novos derivados cumarínicos: um par de enantiômeros de 4-hidroxicumarina (11a-b), um par de enantiômeros com um esqueleto policíclico raro (12a-b) e um análogo de 7-hidroxicumarina (13) (Figura 4). As atividades anticoagulantes dos compostos foram avaliadas in vitro e in vivo através dos ensaios de Tempo de Tromboplastina Parcialmente Ativada (TTPA), Tempo de Trombina (TT) e Tempo de Protrombina (TP). O melhor resultado in vivo (1 mg kg $\mathrm{mg}^{-1}$, administração oral) foi observado para o composto $\mathbf{1 3}$,<smiles>O=c1oc2ccccc2c(O)c1Cc1c(O)c2ccccc2oc1=O</smiles>

3<smiles>CC(=CCC(C)(C)C)CC1(C)C=C(C)C(=O)c2ccccc21</smiles>

Vitamina $\mathrm{K}$<smiles>CC(=O)CC(c1ccccc1)c1c(O)c2ccccc2oc1=O</smiles>

varfarina<smiles>CC(=O)CC(c1ccccc1)C1C(=O)Oc2ccccc2C1=O</smiles>

Inibidor da
B<smiles>[R]c1ccc(C(CCCCCCCCCCC)c2c(O)c3ccccc3oc2=O)c([R])c1</smiles>

$6 \mathbf{a}-\mathrm{R}_{1}=-\mathrm{Cl} ; \mathrm{R}_{2}=-\mathrm{H} ; \mathrm{Ki}=20 \mathrm{nM}^{*}$

$6 b-R_{1}=R_{2}=-C l ; K i=90 n M^{*}$ *atividade anti VKORC1

vitamina K 2,3-epóxido redutase

Figura 2. Estrutura da varfarina (2), dicumarol (3), vitamina $K(4)$ e 5 (A); Derivados 4-hidroxi cumarínicos 6 a-b (B)<smiles>Cc1ccc(-c2cc(-c3ccc(C)cc3)n(C(=O)Nc3ccc4oc(=O)ccc4c3)n2)cc1</smiles>

Figura 3. Derivados $N$-cumarínos com atividade antitrombótica 
que apresentou atividade anticoagulante potente $(\mathrm{TP}=41,2 \mathrm{~s}$ e TT 128,5 s) e sem toxicidade hepática ou renal significativa quando comparado à varfarina ( $\mathrm{TP}=55,7 \mathrm{~s}$ e TT 80,6 s) na mesma dose em ratos Wistar, sendo considerado um agente promissor para avaliação pré-clínica adicional para a prevenção de coagulação sanguínea anormal. ${ }^{26}$

Cumarinas naturais com atividade anticoagulante também foram isoladas de espécies de Ferulago. ${ }^{27,28}$ A espécie Ferulago carduchorum é conhecida como Chavil na Pérsia e cresce no oeste do Irã. ${ }^{29}$ Duas cumarinas (Figura 4) foram isoladas desta planta, suberosina (14) e suberenol (15), as quais prolongaram o TP em doses de 3 e $6 \mathrm{mg} \mathrm{kg}^{-1}$ em relação ao controle $(\mathrm{p}<0,05)$. O TP mais longo foi apresentado por 14 de $17,4 \mathrm{~s}$, a $6 \mathrm{mg} \mathrm{kg}^{-1}$. $^{30}$

\section{COMPOSTOS CUMARÍNICOS ANTICANCER}

Fundamentalmente, o câncer é uma doença genética, consequência de multiplas mutações, acumuladas durante a vida do indivíduo, sejam elas herdadas, espontâneas ou em resposta ao ambiente. ${ }^{31}$ Dentre as capacidades adquiridas pela maioria, se não, todos os tipos de tumores estão: auto-suficiência de sinais de crescimento, insensibilidade à sinalização anti-crescimento, inibição da apoptose, invasão e metástase de tecidos, sustentação da angiogênese e resistência à senescência celular. ${ }^{32}$ Muitos tipos de câncer desenvolveram resistência a quimioterapêuticos, de modo que a descoberta de novos fármacos antitumorais está se tornando cada vez mais necessária.

Os microtúbulos, compostos por heterodímeros de $\alpha$-tubulina e $\beta$-tubulina, são muito importantes no processo de mitose celular, durante o qual os cromossomos duplicados de uma célula se separaram em dois conjuntos idênticos antes da clivagem celular em duas células filhas. ${ }^{33 a-b} \mathrm{O}$ emprego de microtúbulos como alvo terapêutico se mostra uma estratégia importante para o tratamento do câncer. Cao et al, descreveram a síntese de cinquenta e oito novos derivados cumarínicos 4-substituídos. Os resultados de atividade antiproliferativa revelaram que os derivados 16-22 apresentaram alta atividade antiproliferativa, com valores de $\mathrm{CI}_{50}$ (concentração inibitória média) entre 7 e $83 \mathrm{nM}$ frente a todas as linhas celulares tumorais testadas. O composto 21 apresentou maior atividade antiproliferativa $\left(\mathrm{CI}_{50}\right.$ de 7-47 nM) mantendo a atividade total em células de câncer multiresistentes. O composto $\mathbf{2 1}$ atua na fase G2/M e interage com o sítio de ligação da colchicina na tubulina. Adicionalemnte, $\mathbf{2 1}$ reduziu a migração celular e interrompeu a formação de tubos capilares nas células HUVEC, reduzindo também significativamente o crescimento do tumor em modelos de xenoenxertos, incluindo tumores ovarianos sensíveis e resistentes ao paclitaxel. Os resultados sugerem que o composto cumarínico $\mathbf{2 1}$ representa uma nova classe de estabilização de microtúbulos, tornando-se um inibidor promissor para o tratamento do câncer (Figura 5). ${ }^{34}$

$\mathrm{Fu}$ e colaboradores sintetizaram compostos híbridos de trimetoxifenil-1,2,3-triazol, os quais foram avaliados quanto à sua atividade antiproliferativa contra três linhagens de células tumorais (PC3, MGC803 e HepG2). O composto trimetoxifenil-1,2,3-triazol 23 (Figura 5), contendo o núcleo cumarínico, apresentou a maior atividade antiproliferativa, com $\mathrm{CI}_{50}$ de $0,13 \mu \mathrm{M}$ a $1,74 \mu \mathrm{M}$, mais ativo que o padrão colchicina $\mathrm{CI}_{50}$ de $0,27 \mu \mathrm{M}$ a $4,60 \mu \mathrm{M}$. O composto 23 foi capaz de inibir o crescimento celular, induzir parada do ciclo celular na fase G2/M devido a redução da expressão da proteína quinase dependente de ciclinas 1 (CDK1); e promover apoptose através da regulação da expressão de DR5 e Bcl-2. Além disso, 23 foi capaz de inibir a polimerização da tubulina $\left(\mathrm{CI}_{50}=2,16 \mu \mathrm{M}\right)$, através da interação com sítio da colchicina. ${ }^{35}$

As HSP90 são chaperonas ATP-dependentes responsáveis pela ativação e estabilização de mais de 200 proteínas ${ }^{36}$ muitas das quais são relacionadas ao câncer. ${ }^{37 a-b}$ Assim, inibidores da HSP90 são promissores porque podem inibir de maneira indireta várias proteínas oncogênicas simultaneamente, sendo reconhecidas como um alvo terapêutico para o tratamento do câncer. ${ }^{38}$ Atualmente, a maioria dos inibidores $C$-terminais da HSP90 são derivados do novobiocin<smiles>CC(C)=CCC[C@](C)(O)[C@H](C)c1c(O)c2c(C)cccc2oc1=O</smiles>

$11 \mathrm{a}$<smiles>CC(C)=CCC[C@](C)(O)[C@H](C)c1c(O)c2c(C)cccc2oc1=O</smiles>

$11 b$<smiles>Cc1cccc2oc(=O)c3c(c12)OC(C)(C)C1=C3[C@@H](C)[C@](C)(O)CC1</smiles><smiles>Cc1cccc2oc(=O)c3c(c12)OC(C)(C)C1=C3[C@@H](C)[C@](C)(O)CC1</smiles><smiles>COc1c2c(cc3ccc(=O)oc13)[C@H](O)[C@H](C(C)(C)O)O2</smiles><smiles>COc1cc2oc(=O)ccc2cc1CC=C(C)C</smiles><smiles>COc1cc2oc(=O)ccc2cc1/C=C/C(C)(C)O</smiles>

Figura 4. Cumarinas naturais com atividade anticoagulante<smiles>[R]c1cc(N(C)c2cc(=O)oc3ccccc23)ccc1OC</smiles>

$16-22$
16: $\mathrm{R}_{1}=0$-but-2-enil

17: $\mathrm{R}_{1}=0$-(5-metoxi-5-oxopentanil)

18: $R_{1}=0$-(5-cloropentanil)

19: $\mathrm{R}_{1}=\mathrm{O}$ - (5-metilpent-2-enil)

20: $\mathrm{R}_{1}=N$-(5-metoxi-5-oxopentanil)

21: $\mathrm{R}_{1}=N$-(5-cloropentanil)

22: $\mathrm{R}_{1}=N$-pent-4-enil<smiles>COc1ccc(CN(C(=O)Cn2cc(COc3ccc4c(C)cc(=O)oc4c3)nn2)c2cc(OC)c(OC)c(OC)c2)cc1</smiles>

23

Figura 5. Derivados cumarínicos antiproliferativos (16-23) possuindo a tubulina como alvo 
24, ${ }^{39 a-f}$ um produto natural tradicionalmente usado como antibiótico. Estudos anteriores a respeito da relação estrutura-atividade (REA) do Novobiocin (24, Figura 6) demonstraram a importância do grupamento amida para a atividade inibitória da HSP90 ${ }^{39}$ e sugeriram a importância de realizar ligação de hidrogênio adicional para alcançar a atividade antiproliferativa, em detrimento à resposta de choque térmico. ${ }^{39 b-c}$ Além disso, foi demonstrado que o grupo noviose não era importante para a inibição e poderia ser substituído por um grupo alquil-amino com distância de 3 carbonos entre amina e oxigênio da cumarina para aprimorar as atividades. ${ }^{39 \mathrm{e}}$

Zhao e colaboradores sintetizaram uma série de análogos cumarínico 1,2,3-triazois (25-29), seguida da avaliação da atividade antiproliferativas frente a linhagens de células de câncer de mama (SKBr3, MDA-MB-468LN e MCF-7), próstata (PC3-MM2 e LNCaP) e carcinoma escamoso de cabeça e pescoço (MDA1986 e JMAR). Os resultados demonstraram que esses análogos apresentaram potências antiproliferativas na faixa de nanomolar, indicando que interações do tipo ligação de hidrogênio na cadeia lateral eram favoráveis para a inibição $C$-terminal da HSP90. Ademais, os resultados mostraram que a presença de substituintes benzílicos com grupos retiradores de elétrons ligado ao triazol melhoram as atividades, sendo que 29 (Figura 7) apresentou $\mathrm{CI}_{50}$ de $0,38 \mu \mathrm{M}$ e $0,64 \mu \mathrm{M}$ frente a linhagens celulares SKBr3 e MCF-7, respectivamente. Resultados de Western Blot mostraram que as proteínas clientes da HSP90 (Her2, Akt e Raf1) foram degradadas após a exposição às cumarinas em concentrações semelhantes a seus valores antiproliferativos, concluindo que a viabilidade celular está diretamente ligada à inibição da HSP90. ${ }^{40}$

Visando o mesmo alvo, uma série de compostos de pirazolinocumarinas 30a-f (Figura 7) foram sintetizadas e avaliadas como antitumorais frente a células de câncer de pulmão A549. As interações entre 30a-f e HSP90 foram examinadas in silico através da estrutura cristalina da HSP90 (PDB ID: 1YET) e in vitro por imunoprecipitação. Todos os compostos (30a-f) reduziram a viabilidade das células A549 $\left(\mathrm{CI}_{50}=4,7-9,6 \mu \mathrm{M}\right)$ e os resultados de imunoprecipitação mostraram que os compostos bloquearam a ligação entre a HSP90 com o anticorpo, sugerindo que estes podem se ligar diretamente a HSP90. Análises por docking mostraram que os derivados poderiam interagir com a HSP90 no sítio catalítico da ATPase no domínio $N$-terminal da HSP90, ou seja, de forma diferente dos inibidores da HSP90 descritos anteriormente. O resultado de Western blot mostrou que o tratamento com 30a a $10 \mu \mathrm{M}$ diminuiu significativamente os níveis de proteínas AKT e NFkB (p65) sem alterar o nível de proteína HSP90, a saber, AKT e Ikb são proteínas clientes de HSP90, enquanto NFkB (p65) é uma proteína a jusante (downstream) de Ikb. ${ }^{41}$

As histonas desacetilases (HDACs) desempenham um papel importante na regulação transcricional epigenética, ${ }^{42}$ já que são responsáveis por catalisar a desacetilação de resíduos de $\varepsilon$ - $N$-acetil lisina de proteínas histona, e também em proteínas não histônicas. ${ }^{43 a-b}$ A desacetilação de resíduos de lisina nas proteínas das histonas leva à condensação da cromatina e repressão da transcricional. ${ }^{44}$ Ademais, as HDACs encontra-se super expressas em vários tipos de câncer, tendo efeito sobre diversos oncogenes e genes supressores de tumores. ${ }^{45}$ Assim, o uso de inibidores das HDACs tem se destacado como estratégia promissora para o tratamento anticâncer.

Uma série de benzamidas baseadas no núcleo cumarínico foram planejadas como inibidores de HDAC. A atividade citotóxica dos vinte e um compostos sintetizados foi avaliada contra seis linhagens de células de câncer humano incluindo HCT116, A2780, MCF7, PC3, HL60 e A549 e célula normal (Huvec), e quatro compostos (31a, 31b, 31c e 31d) mostraram citotoxicidade significativa com $\mathrm{CI}_{50}$ entre $0,53 \mu \mathrm{M}$ e $57,59 \mu \mathrm{M}$ nestas células. Ademais, estes compostos apresentaram pronunciada inibição em modelo de pan-HDAC $\left(\mathrm{CI}_{50}=0,80-14,81 \mu \mathrm{M}\right)$ e também em modelo de HDAC1 isolada $\left(\mathrm{CI}_{50}=0,47 \mu \mathrm{M}\right.$ e $\left.0,87 \mu \mathrm{M}\right)$, demonstrando ausência de efeito sobre viabilidade de células Huvec $\left(\mathrm{CI}_{50}>100 \mu \mathrm{M}\right)$. Destaque para 31d (Figura 8) que apresentou maior potência de inibição de HDAC1 $\left(\mathrm{CI}_{50}\right.$ de $\left.0,47 \mu \mathrm{M}\right)$, próximo ao medicamento de referência Entinostat $\left(\mathrm{CI}_{50}\right.$ de $\left.0,41 \mu \mathrm{M}\right)$. Essas descobertas sugeriram que os derivados da cumarina são protótipos promissores para o desenvolvimento de compostos antitumorais como inibidores de HDACs. ${ }^{46}$

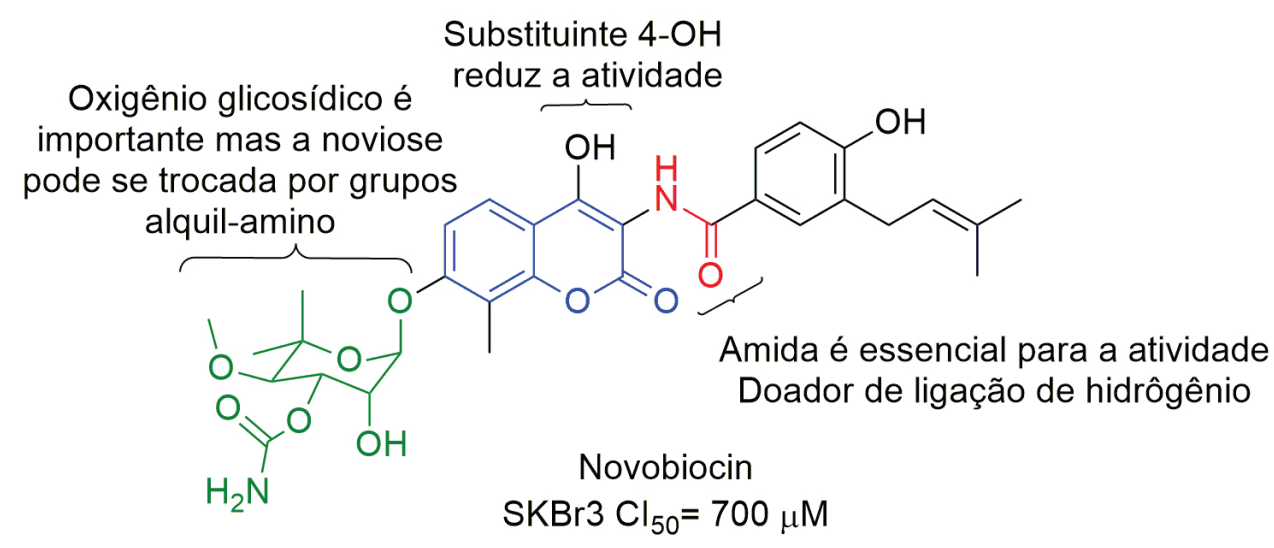

Figura 6. Relação estrutura-atividade (REA) do Novobiocin (24)

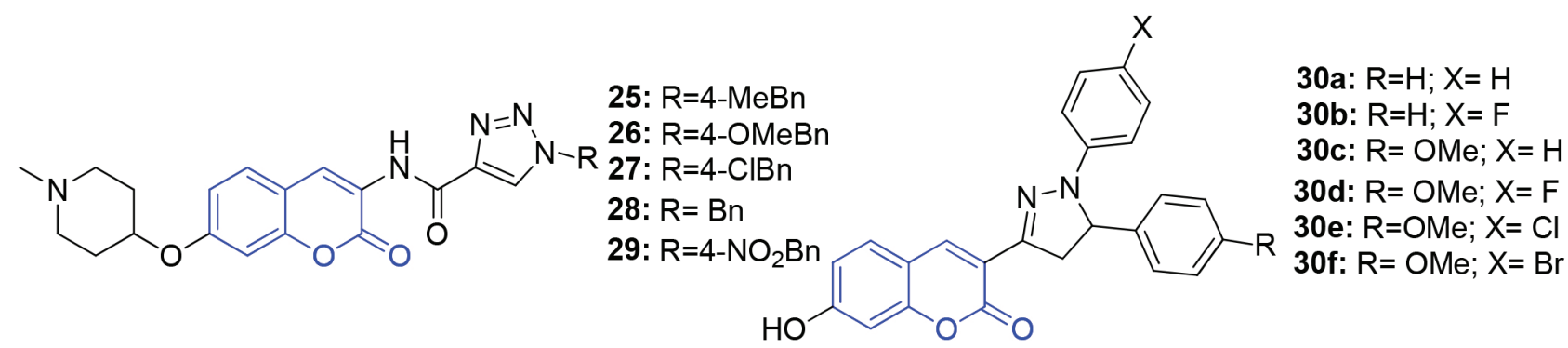

Figura 7. Série de compostos 1,2,3-triazol (25-29) e pirazolino-cumarinas (30a-f) como inibidores de HSP90 
<smiles>[R]c1cc2cc(C(=O)NCc3ccc(C(=O)Nc4ccccc4N)cc3)c(=O)oc2c([R])c1[R]</smiles>

31a: $\mathrm{R}_{1}=\mathrm{H} ; \mathrm{R}_{2}=\mathrm{OCH}_{2} \mathrm{CH}_{2} \mathrm{CH}_{3} ; \mathrm{R}_{3}=\mathrm{H}\left(\mathrm{HDAC} 1 \mathrm{Cl}_{50}=0,87 \mu \mathrm{M}\right)$

31b: $\mathrm{R}_{1}=\mathrm{H} ; \mathrm{R}_{2}=4-\mathrm{Br}$-benziloxi; $\mathrm{R}_{3}=\mathrm{H}\left(\mathrm{HDAC} 1 \mathrm{Cl}_{50}=0,50 \mu \mathrm{M}\right)$

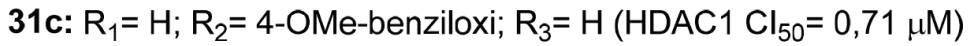

31d: $R_{1}=H ; R_{2}=3,4-d i-C l-b e n z i l o x i ; R_{3}=H\left(H D A C 1 C_{50}=0,47 \mu M\right)$

Figura 8. Nova série de benzamidas de cumarina (31a-d) como inibidores da HDAC

As anidrases carbônicas humanas (hCA) são metaloenzimas que regulam funções fisiológicas ligadas ao transporte de dióxido de carbono / bicarbonato, $\mathrm{pH}$, secreção de eletrólitos e reações biossintéticas. ${ }^{47 \mathrm{a}-\mathrm{b}}$ Em tumores sólidos, as células em divisão criam condições hipóxicas que eventualmente levam a uma acidez do microambiente, que consequentemente induzem a superexpressão das isoformas hCA IX e XII. ${ }^{47 b}$ Ambas as isoformas auxiliam na manutenção do $\mathrm{pH}$ intracelular mais alcalino, contribuindo para a progressão do tumor, ${ }^{48 a-c}$ sendo alvos em potencial para terapia antitumoral. ${ }^{49 \mathrm{a}-\mathrm{d}}$

Bonardi e colaboradores descreveram a síntese de um conjunto de derivados cumarínicos (32) e cromeno [4,3-c] pirazol-4-onas (33-41), e avaliação frente as hCAs IX e XII associadas a tumores e as isoformas citosólicas hCAs I e II. Um conjunto de derivados (34, 36, 37, 39, 40 e 41) (Figura 9) apresentaram valores de Ki na faixa de nanomolar ( $\mathrm{Ki}<41 \mathrm{nM}$ ), sendo seletivo frente a hCA IX, enquanto outro grupo de compostos $(32,33$ e 38) agiram como inibidores duplos das hCA IX e XII ( $\mathrm{Ki}=5,6-9,6 \mathrm{nM})$, e nenhum foi eficaz frente as isoformas hCA I e II. Alguns inibidores selecionados $(\mathbf{3 2}, \mathbf{3 5}, \mathbf{3 6}, \mathbf{3 9}, \mathbf{4 0}$ e 41) mostraram atividade antiproliferativa em linhagens celulares HT-29, tanto em condições normóxicas quanto hipóxicas. Esses resultados sugerem que, possivelmente, tais derivados atuem através de mais de um mecanismo de ação, envolvendo a inibição das hCAs IX e XII em hipóxia, além de outros alvos não identificados em normóxia. ${ }^{50}$

Visando o mesmo alvo, uma série de novas dihidroartemisininocumarinas híbridas apresentaram atividade contra duas linhagens celulares tumorais (MDA-MB-231 e HT-29). O estudo da relação estrutura-atividade dos derivados mostrou que de maneira geral substituintes 3-cloro $\left(\mathrm{R}_{2}\right)$ e 4-metil $\left(\mathrm{R}_{1}\right)$ ligados a cumarina geralmente apresentavam melhores atividades, enquanto grupos 3-etoxicarbonil
$\left(\mathrm{R}_{2}\right)$ e 3-metoxicarbonil $\left(\mathrm{R}_{2}\right)$ levavam a redução das mesmas. As séries com espaçadores (43-48) (Figura 9) apresentaram maiores atividades que os compostos da série 42, sendo que os compostos que continham o núcleo 1,2,3-triazol demonstraram melhor perfil de citotoxicidade do que os demais, apresentando $\mathrm{CI}_{50}$ de até $20 \mathrm{nM}$ (composto 47 sendo $\mathrm{R}_{1}=\mathrm{R}_{2}=\mathrm{CH}_{3}$ ) frente a células HT-29, quando em condições de hipóxia. Estudos de docking molecular entre os derivados cumarínicos hidrolizados (exemplo 48a, que ocorre no sítio da CA) e o sítio ativo da CA IX demonstrou que a cumarina hidrolisada (hidólise da lactona da cumarina) poderia interagir por ligações de hidrogênio com His-96, His-119, Thr-199, Thr-200, enquanto o núcleo triazol faria também ligações de hidrogênio com Asn-62 e Gln-67, explicando a melhor atividade quando da presença dos triazois. Ademais, esses derivados foram capazes de interromper a fase G0/G1 das células HT-29, suprimir a migração de células tumorais e induzir uma grande redução no potencial da membrana mitocondrial, levando à apoptose de células tumorais, bem como induzir morte celular via ferroptose. ${ }^{51}$

As proteínas quinases (KPts) fosforilam especificamente outras proteínas, levando à ativação de caminhos de transdução de sinal intracelular, fundamentais em múltiplos processos biológicos, incluindo crescimento, diferenciação e apoptose, porém sua desregulação e sobreexpreção é características de células tumorais. Receptores do fator de crescimento vascular endotelial (VEGFR) são essenciais no processo da angiogênese, entretanto sua superativação está associada à progressão de diversos tipos de cânceres humanos, sendo vantajoso o emprego de inibidores VEGFR quinase no tratamento do câncer. ${ }^{52 \mathrm{a}-\mathrm{b}}$

Ahmed e coloboradores descreveram a síntese de derivados cumarínicos e avaliação in vitro da atividade antiproliferativa contra<smiles>CC(=O)c1c(O)c2cc(Br)ccc2oc1=O</smiles>
32 $\mathrm{hCAIX} \mathrm{K}=8,2 \mathrm{nM}$ hCAXII $\mathrm{K}_{\mathrm{i}}=5,6 \mathrm{nM}$

45: $n=2 ; 46: n=3$

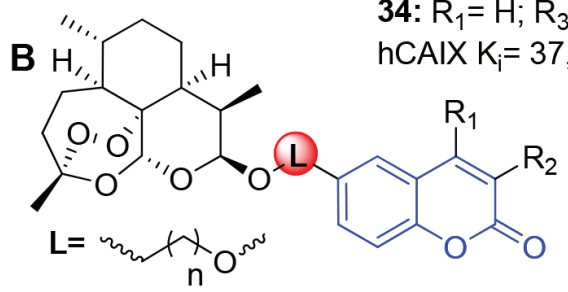<smiles>[R]c1ccc2oc(=O)c3c([R3])n(-c4ccccc4)nc3c2c1</smiles>

33: $\mathrm{R}_{1}=\mathrm{Br} ; \mathrm{R}_{3}=\mathrm{Me}$ hCAIX $K_{i}=25,2$ nM 34: $\mathrm{R}_{1}=\mathrm{H} ; \mathrm{R}_{3}=\mathrm{H}$ hCAIX Ki $=37,6 \mathrm{nM}$ M<smiles>[R2]c1ccc(-n2nc(C)c3c(=O)oc4c([R])cccc4c32)cc1</smiles>

35: $\mathrm{R}_{1}=\mathrm{H} ; \mathrm{R}_{2}=\mathrm{H}\left(\mathrm{hCAIX} \mathrm{K}_{\mathrm{i}}=9,5 \mathrm{nM}\right.$ hCAXII $\left.\mathrm{K}_{\mathrm{i}}=5,8 \mathrm{nM}\right)$

36: $\mathrm{R}_{1}=\mathrm{H} ; \mathrm{R}_{2}=4-\mathrm{Me}\left(\mathrm{hCAIX} \mathrm{K}_{\mathrm{i}}=22,2 \mathrm{nM}\right)$

37: $\mathrm{R}_{1}=\mathrm{H} ; \mathrm{R}_{2}=4-\mathrm{MeO}(\mathrm{hCAIX} \mathrm{K}=40,2 \mathrm{nM}$ )

38: $\mathrm{R}_{1}=\mathrm{Br} ; \mathrm{R}_{2}=\mathrm{H}\left(\mathrm{hCAIX} \mathrm{K}_{\mathrm{i}}=8,5 \mathrm{nM}\right.$ hCAXII $\mathrm{K}_{\mathrm{i}}=7,1 \mathrm{nM}$ )

39: $\mathrm{R}_{1}=\mathrm{NO}_{2} ; \mathrm{R}_{2}=\mathrm{H}(\mathrm{hCAIX} \mathrm{K}=27,1 \mathrm{nM})$

40: $\mathrm{R}_{1}=\mathrm{NH}_{2} ; \mathrm{R}_{2}=\mathrm{H}(\mathrm{hCAIX} \mathrm{K}=34,5 \mathrm{nM})$

41: $R_{1}=$ NHCOPh; $R_{2}=H\left(h C A I X K_{i}=15,3 n M\right)$<smiles>CCC</smiles><smiles></smiles>

43: $n=2 ; 44: n=3$ 
linhagens de células MCF-7 de câncer de mama e PC-3 de câncer de próstata, bem como da atividade inibidora de VEGFR-2 quinase. Os compostos exibiram citotoxicidade contra células MCF-7, entretanto, não mostraram atividade citotóxica significativa contra células PC-3. Os dois compostos com maior atividade citotóxica contra MCF-7, 49a (Figura 10) $\left(\mathrm{CI}_{50}=1,24 \mu \mathrm{M}\right)$ e $49 \mathrm{~b}$ (Figura 10) $\left(\mathrm{CI}_{50}=1,65 \mu \mathrm{M}\right)$, foram avaliados quanto ao seu efeito na inibição do VEGFR-2 e os resultados mostraram valores de $\mathrm{CI}_{50}$ iguais a $0,36 \mu \mathrm{M}$ e $0,66 \mu \mathrm{M}$, respectivamente. Além disso, o composto 49a foi capaz de induzir apoptose pré-G1, parar o crescimento celular na fase G2/M e ativar a caspase-9. Os estudos de docking molecular demonstraram a capacidade do composto 49a interagir com os principais resíduos de aminoácidos do sítio de ligação da VEGFR-2 quinase. E por fim, observou-se in silico que o composto 49a possui propriedades ADMET muito satisfatórias, além de não violar a regra dos cinco de Lipinski. ${ }^{53}$

\section{COMPOSTOS CUMARÍNICOS} ANTINEURODEGENERATIVOS

Doença neurodegerativa é um termo utilizado para descrever um conjunto de doenças onde há a deterioração do sistema nervoso de forma progressiva e irreversível. Muitos são os fatores associados a essas doenças, incluindo agregação de proteínas, mutações genéticas, fisiopatologias, estresse oxidativo, lesão mitocondrial, dentre outros fatores. Em geral, são consideradas doenças complexas, pois envolvem uma série de cascatas de sinalizações conhecidas e desconhecidas. As doenças neurodegenerativas mais comuns são a Doença de Alzheimer (DA), Doença de Parkinson (DP), Esclerose Lateral Amiotrófica (ELA), Doença de Huntington (DH) e Doença Priônica. ${ }^{54-c}$ Nesta revisão focaremos na DA, onde encontramos o maior número de relatos com cumarinas.

\section{Compostos cumarínicos com atividades anti-Alzheimer}

A Doença de Alzheimer (DA) é uma doença neurodegenerativa progressiva, sendo atualmente a forma mais comum de demência em idosos, caracterizada pela perda de memória e diversas funções cognitivas. A DA é uma doença de etiopatogenia complexa e multifatorial, onde os fatores mais aceitos são a deposição $\beta$-amilóide $(\mathrm{A} \beta)$, hipofunção colinérgica, emaranhados neurofibrilares, estresse oxidativo, neuroinflamação, entre outros. ${ }^{55}$

A hipótese colinérgica da DA afirma que a degeneração dos neurônios colinérgicos nos núcleos do prosencéfalo basal provoca distúrbios nos terminais colinérgicos pré-sinápticos no hipocampo e no neocórtex, que são regiões de extrema importância para distúrbios de memória e outros sintomas cognitivos. ${ }^{56}$ Como resultado da neurodegenaração, a atividade de neurônios colinérgicos, aqueles que utilizam o neurotransmissor acetilcolina $(\mathrm{ACh})$, é reduzida. Uma abordagem terapêutica para melhorar a neurotransmissão colinérgica é aumentar a disponibilidade de ACh pela inibição da acetilcolinesterase (AChE) e butirilcolinestere $(\mathrm{BuChE})$, enzimas que degradam a acetilcolina na fenda sináptica. ${ }^{57 a-c}$

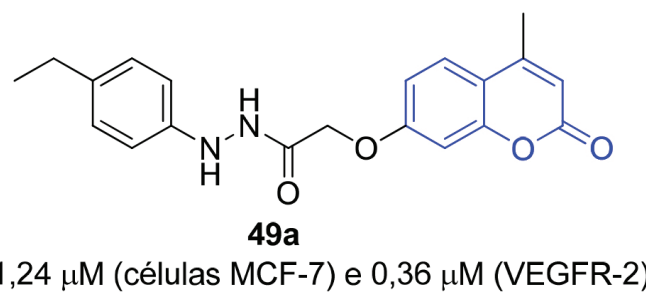

Recentemente, Shi e colaboradores desenvolveram uma nova série híbrida de cumarina-carbazol, que se apresentaram como promissores inibidores de colinesterase. Dentre os compostos, 50a (Figura 11) se destacou por ter sido o derivado que apresentou maior potencial de inibição para AChE (eeAChE: $\mathrm{CI}_{50}=3,75 \mu \mathrm{M}$; hAChE: $\mathrm{CI}_{50}=70,51 \mu \mathrm{M}$ ), além de ter demonstrado ser altamente seletivo para $\mathrm{AChE}$ em relação a BuChE, já que não foi capaz de inibir mais que $30 \%$ da eqBChE ou hBChE na concentração de $50 \mu \mathrm{M}$. Estudos de modelagem molecular sugeriram que 50a pode interagir com dois sítios de ligação diferentes na AChE, o CAS e o PAS, o que resulta na sua maior potência de inibição. O composto ainda foi avaliado frente à sua capacidade antioxidante utilizando como padrão o Trolox, um análogo a vitamina E, onde 50a demonstrou possuir capacidade antioxidante inferior ao do padrão utilizado. ${ }^{58}$

Najafi e colaboradores desenvolveram uma nova série híbrida de cumarina-tacrina usando o núcleo 1,2,3-triazólico como espaçadores, que se apresentaram como promissores inibidores de colinesterases. Dentre os compostos, 50b se destacou por ter sido o derivado que apresentou maior potencial de inibição para $\mathrm{AChE}\left(\mathrm{CI}_{50}=27 \mathrm{nM}\right)$, enquanto 50c exibiu a melhor atividade inibidora de BuChE $\left(\mathrm{CI}_{50}=6 \mathrm{nM}\right)$. Esses valores demostraram que 50c é muito mais ativo como iBuChE do que a tacrina $\left(\mathrm{CI}_{50}=10 \mathrm{nM}\right)$ e o donepezil $\left(\mathrm{CI}_{50}=8,4 \mu \mathrm{M}\right)$, fármacos usados como referência. O composto 50b ainda foi avaliado frente à inibição de BACE1, demonstrando atividade inibitória moderada. Além disso, a neuroprotetividade de 50b contra células PC12 expostas a A $\beta 25-35$ foi baixa. Os autores também relataram os estudos in vivo do labirinto aquático de Morris, onde 50b foi capaz de reverter de forma significativa o deficit de memória induzida por escopolamina em ratos. ${ }^{59}$

Nosso grupo desenvolveu uma série de 7-aminoalcoxi-cumarinas como inibidoras de colinesterases e antioxidantes. Os ensaios in vitro indicaram que todos os compostos propostos foram eficazes na inibição da $\mathrm{AChE}$, com potências na faixa nanomolar. Dentre os compostos, a 3-(4-(dimetilamino)fenil)-7-aminoetoxi-cumarina (51e) (Figura 11) se destacou com o resultado mais promissor, tendo demonstrado alto potencial de inibição da $\mathrm{AChE}\left(\mathrm{CI}_{50}=20 \mathrm{nM}\right) \mathrm{e}$ uma seletividade $\left(\mathrm{CI}_{50} \mathrm{BuChE} / \mathrm{AChE}=354\right)$ muito semelhante a do composto de referência, o donepezil $\left(\mathrm{CI}_{50} \mathrm{AChE}=6 \mathrm{nM}\right.$; $\left.\mathrm{CI}_{50} \mathrm{BuChE} / \mathrm{AChE}=365\right)$. 51e também apresentou propriedades antioxidantes, baixa citotoxicidade e boas propriedades ADMET. Avaliações de cinética e modelagem molecular definiram o modo de ação (tipo misto) e importância de 2 metilenos espaçadores entre a cumarina e a piperidina, assim como a presença do núcleo dimetilamino-fenila em C-3 da cumarina. ${ }^{60}$

As Monoamina Oxidases (MAO) são enzimas contendo flavina adenina dinucleótideo (FAD) que catalisam a desaminação oxidativa das monoaminas. A MAO existe sob duas isoformas enzimáticas diferentes, designadas como MAO-A e MAO-B e estão localizadas na membrana mitocondrial externa de quase todos os tecidos. ${ }^{61}$ No cérebro, a MAO se localiza na glia, neurônios e outras células. ${ }^{62}$ sendo que a MAO B é comumentemente elevada em pacientes com DA, levando a uma maior metabolização da dopamina e à produção<smiles>Cc1cc(=O)oc2cc(OCC(=O)Nn3c(=O)[nH]c4ccccc4c3=O)ccc12</smiles>

$49 b$

$\mathrm{Cl}_{50}=1,65 \mu \mathrm{M}$ (células MCF-7) e 0,66 $\mu \mathrm{M}$ (VEGFR-2)

Figura 10. Compostos cumarínicos com atividade antiproliferativa, inibidores de VEGFR-2 (49a-b) 
de grandes quantidades de peróxido de hidrogênio e radicais livres que, em última instância, originam dano neuronal. ${ }^{63-64}$ Dessa forma, as estratégias terapêuticas até o momento baseam-se no aumento dos níveis de dopamina no cerébro pela administração do precursor da dopamina, a levodopa ou de algum inibidor da MAO-B. ${ }^{62,65}$

Compostos híbridos cumarina-ditiocarbamato foram planejados como inibidores multifatoriais pela inibição da AChE e MAO para o tratamento da DA. Neste estudo, foi constatado que dentre os compostos sintetizados, 52a (Figura 11) apresentou o maior potencial inibidor da $\mathrm{AChE}$ com valores de $\mathrm{CI}_{50}$ de $0,009 \mu \mathrm{M}$ para hAChE. Ainda foi observado que o composto 52b (Figura 11), além de ser identificado como o inibidor mais potente da hMAO-B $\left(\mathrm{CI}_{50}=0,10 \mu \mathrm{M}\right)$, também apresentou bom potencial inibidor da $\mathrm{hAChE}\left(\mathrm{CI}_{50}=0,11 \mu \mathrm{M}\right)$, permeabilidade ao sistema nervoso central e ausência de neurotoxicidade em células SH-SY5Y. Estudos de modelagem molecular e cinética, demonstraram que 52b é um inibidor misto da AChE e um inibidor competitivo da MAO-B. ${ }^{66}$

O peptídeo $\beta$-amilóide é um dos componentes principais das placas senis e emaranhados fibrilares que constituem uma das características neuro histopatológica da DA. Uma superprodução de peptídeo $\mathrm{A} \beta$ e sua posterior deposição em placas amilóides insolúveis em regiões específicas do cérebro, como o córtex cerebral e o hipocampo, responsáveis pelas funções cognitivas, ${ }^{67}$ podem representar a rota patológica chave desta doença. Assim, o peptídeo A $\beta$ tornou-se um dos alvos principais para o desenvolvimento de terapias eficazes para a DA. ${ }^{68}$

El-Sayed e colaboradores investigaram o potencial inibidor de novos derivados de fosfazida como inibidores de acetilcolinesterase (AChE) e agregação $\beta$-amiloide. Dos compostos testados, o derivado cumarínico $\mathbf{5 3}$ apresentou uns dos maiores potenciais de inibição para $\mathrm{AChE}\left(\mathrm{CI}_{50}=34,96 \mathrm{nM}\right)$, além do melhor índice de seletividade $\left(\mathrm{CI}_{50} \mathrm{BuChE} / \mathrm{AChE}=3,81\right)$. Além disso, o composto 53 (Figura 12) demonstrou uma boa capacidade de inibição frente à MMP-2 $\left(\mathrm{CI}_{50}=441,33 \mathrm{nM}\right)$ e da agregação auto-induzida de $\mathrm{A} \beta_{1-42}$ $\left(\mathrm{CI}_{50}=337,77 \mathrm{nM}\right)$. O composto $\mathbf{5 3}$ também foi avaliado quanto a sua capacidade de quelação de metal e de inibição da agregação de $A \beta$ induzida por metal usando fluorescência de tioflavina $T$, demonstrando capacidade de quelação significativa e com maior potencial na agregação de $\mathrm{A} \beta_{42}$ induzida por $\mathrm{Zn}^{2+}$. Além de possuir baixa toxicidade nas células do neuroblastoma SH-SY5Y. ${ }^{69}$

\section{COMPOSTOS CUMARÍNICOS ANTIOXIDANTES}

Radicais livres são derivados de processos metabólicos normais no corpo de uma pessoa ou oriundos de fatores externos. Em geral, esses radicais livres são derivados de moléculas com átomos de oxigênio, nitrogênio ou enxofre, denominadas como espécies reativas de oxigênio (ERO), de nitrogênio (ERN) ou de enxofre (ERS).$^{70}$ Espécies reativas têm importante função biológica como na fagocitose. Por outro lado, quando sua produção é exacerbada, um estresse oxidativo é capaz de danificar células saudáveis podendo levá-las a apoptose. Os radicais livres induzem dano celular pela alteração de atividades biológicas essenciais em lipídios, proteínas, DNA e carboidratos. As células afetadas podem danificar tecidos, e simultaneamente também podem causar um desequilíbrio iônico e disfunção mitocondrial, ${ }^{71}$ contribuindo significativamente para o desenvolvimento de doenças inflamatórias, cardiovasculares, câncer e DA. ${ }^{72 \mathrm{a}-\mathrm{d}}$

Hidroxicumarinas têm demonstrado capacidade antioxidante significativa contra os radicais peroxila gerados pela reação do AAPH [dicloreto de 2,2'-azobis(2-amidinopropano)] com oxigênio atmosférico. ${ }^{73}$ Recentemente, atividades antioxidantes atípicas de
A<smiles>O=c1cc(OCCCCn2c3ccccc3c3ccccc32)c2ccccc2o1</smiles>

$\mathrm{AChE} \mathrm{Cl} \mathrm{S}_{50}=3,75 \mu \mathrm{M}$

c<smiles>[R]C1CCCC(C)N1C(=S)SCCCCOc1ccc2c(C)c(Cl)c(=O)oc2c1</smiles>

52a: $\mathrm{R}_{1}=\mathrm{H} ; \mathrm{AChE} \mathrm{Cl} 50=0,009 \mu \mathrm{M}$

52b: $\mathrm{R}_{1}=\mathrm{CH}_{3} ; \mathrm{AChE} \mathrm{Cl}_{50}=0,11 \mu \mathrm{M} ; \mathrm{MAO}-\mathrm{B}$

$\mathrm{Cl}_{50}=0,10 \mu \mathrm{M}$
B<smiles>[R]c1ccc2c(NCc3cn(CCCOc4ccc5c([R])cc(=O)oc5c4)nn3)c3c(nc2c1)CCCC3</smiles>

50b: $\mathrm{R}_{1}=\mathrm{Cl} ; \mathrm{R}_{2}=\mathrm{CH}_{3} ; \mathrm{AChE} \mathrm{Cl}_{50}=27 \mathrm{nM}$

50c: $\mathrm{R}_{1}=\mathrm{H} ; \mathrm{R}_{2}=\mathrm{H} ; \mathrm{BChE} \mathrm{Cl}_{50}=6 \mathrm{nM}$<smiles>[R]c1cc2ccc(OCC(=C)N3CCCCC3)cc2oc1=O</smiles>

51a: $\mathrm{R}=\mathrm{Br} ; \mathrm{n}=1 ; \mathrm{AChE} \mathrm{Cl} 50=180$ $\mathrm{nM} ; \mathrm{BChE} \mathrm{Cl}_{50}=8370 \mathrm{nM}$ 51b: $\mathrm{R}=\mathrm{Br} ; \mathrm{n}=2 ; \mathrm{AChE} \mathrm{Cl}_{50}=370$ $\mathrm{nM} ; \mathrm{BChE} \mathrm{Cl}_{50}=15870 \mathrm{nM}$ 51c: $\mathrm{R}=\mathrm{Br} ; \mathrm{n}=4 ; \mathrm{AChE} \mathrm{Cl}_{50}=150$ $\mathrm{nM} ; \mathrm{BChE} \mathrm{Cl}_{50}=5010 \mathrm{nM}$

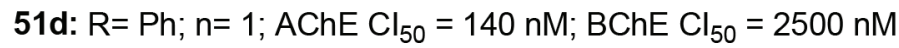

51e: $\mathrm{R}=4-\left(\mathrm{CH}_{3}\right)_{2} \mathrm{~N}-\mathrm{Ph} ; \mathrm{n}=1 ; \mathrm{AChE} \mathrm{Cl}_{50}=20 \mathrm{nM} ; \mathrm{BChE} \mathrm{Cl}_{50}=$ $6730 \mathrm{nM}$

Figura 11. Derivados cumarínicos inibidores de colinesterases $(A)$ e (B) e de MAO (C)<smiles>O=c1cc(N=NN[PH](CCP(=N/N=N/c2cc(=O)oc3ccccc23)(c2ccccc2)c2ccccc2)(c2ccccc2)c2ccccc2)c2ccccc2o1</smiles> 
amino-cumarinas não fenólicas (54) (Figura 13), frente ao AAPH sob condições aeróbicas foram relatadas. Este comportamento foi atribuído à presença de traços de ácido hidroxicinâmico (54b) oriundos de hidrólise. Estudos cinéticos e teóricos baseados na Teoria do Funcional da Densidade apóiam a formação de ácido hidroxicinâmico (54b) e vinculam diretamente o comportamento antioxidante dos compostos à transferência de átomos de hidrogênio como descrito na Figura 13. Essa hipótese permitiu estabelecer um novo comportamento antioxidante para cumarinas com potenciais usos em farmacologia. ${ }^{74}$

Gong e colaboradores relataram a síntese de derivados cumarinooxadiazóis (55-58) capazes de inibir a oxidação do DNA causada pelo AAPH. Os compostos foram testados a uma concentração de $0,4 \mathrm{mM}$ e comparados com os padrões cumarínicos 8,9-diidroxi6H-benzofuro[3,2-c]cromen-6-ona (59a) e 3-(5-( $m, p$-diidroxifenil)1-fenil-4,5-diidro-1H-pirazol-3-il)cromen-2-ona (59b) com valores de $\mathrm{n}$ (fator estequiométrico da oxidação de DNA induzida por AAPH) iguais a 3,39 e 6,60, respectivamente. ${ }^{75}$ Ao comparar o valor n nos cumarino-oxadiazóis, nitidamente a posição e quantidade de hidroxilas influência no aumento desse fator, onde individualmente a substituição em para é a que teria maior influência (Figura 14).

A natureza é uma fonte importante de cumarinas e 23 cumarinas já elucidadas pela literatura e 3 inéditas foram extraídas de raízes de Angelica dahurica (frequentemente como erva medicinal em países asiáticos). Os compostos foram testados no ensaio de ABTS [2,2'-azino-bis(3-etilbenzotiazolin) 6-ácido sulfônico] usando Trolox como controle positivo. $\mathrm{O}$ valor de $\mathrm{CE}_{50}$ (concentração eficaz para $50 \%$ da resposta) para a fração do extrato da raiz em acetato de etila foi $80,45 \mu \mathrm{g} \mathrm{mL}^{-1}$ e $\mathbf{6 0 a}$ (Figura 14) foi o composto isolado mais promissor com um valor de $\mathrm{CE}_{50}$ de $6,44 \mu \mathrm{M} .^{76}$

Uma série de compostos 1,2,3-triazol-1,4-dissubstituídos baseados no núcleo cumarínico foi sintetizada e teve suas propriedades antioxidantes mensuradas a partir dos ensaios de eliminação de radicais DPPH, tendo o ácido ascórbico como padrão. Os valores de $\mathrm{CI}_{50}$ para a atividade antioxidante variou de 343 a $0,06 \mu \mathrm{M}$, onde o composto 60b (Figura 14) apresentou a melhor atividade, o que foi atribuído a presença dos grupos doadores de elétrons - $\mathrm{OMe}$ e $-\mathrm{CH}_{3}$. Em termos comparativos, $\mathbf{6 0 b}$ se mostrou mais potente do que a referência ácido ascórbico $\left(\mathrm{CI}_{50}=1,46 \mu \mathrm{M}\right){ }^{77}$

\section{CUMARINAS ANTIVIRAIS}

Vírus são agentes infecciosos que não são considerados organismo, mas sim parasita intracelular que depende da célula para se multiplicar. Mais da metade das epidemias infecciosas são causadas por infecções virais e entre mais de 3600 tipos de vírus conhecidos, ao menos 1200 podem causar algum tipo de doença. Entre os tipos de vírus mais representativos estão o HIV (do inglês "human immunodeficiency virus" - vírus da imunodeficiência humana), $\mathrm{HCV}$ (do inglês "hepatitis C virus" - vírus da hepatite C) e o vírus

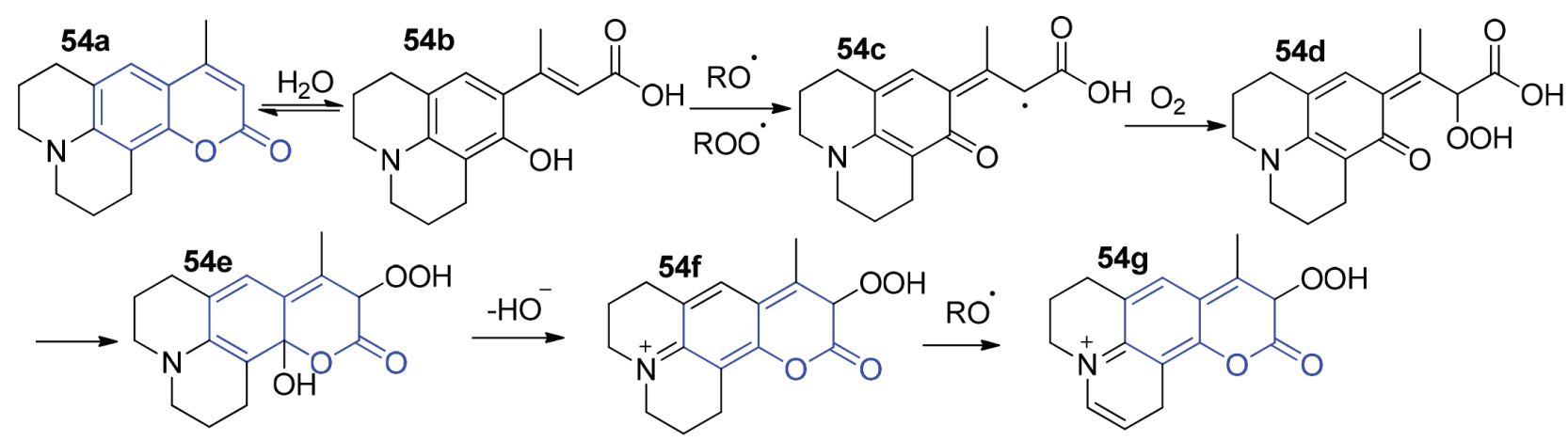

Figura 13. Mecanismo proposto para ação oxidante de amino-cumarinas não fenólicas<smiles>[R]c1ccc(-c2noc(-c3cc4ccccc4oc3=O)n2)cc1</smiles>

55: $\mathrm{R}=3-\mathrm{OH}(\mathrm{n}=0,74)$

56: $\mathrm{R}=4-\mathrm{OH}(\mathrm{n}=3,12)$

57: $\mathrm{R}=3,4-\mathrm{OH}(\mathrm{n}=6,62)$

58: $\mathrm{R}=2,4,5-\mathrm{OH}(\mathrm{n}=8,57)$

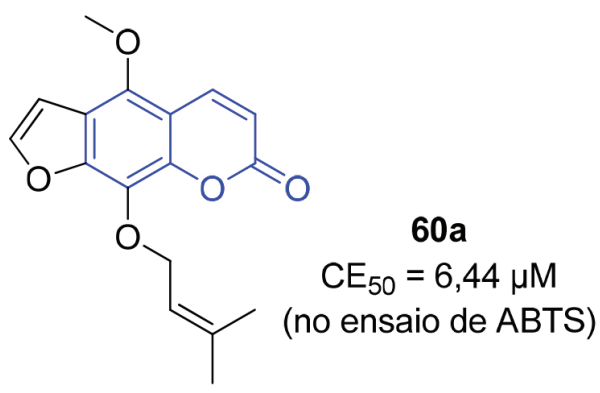<smiles>O=c1oc2ccccc2c2oc3cc(O)c(O)cc3c12</smiles>

$59 a(n=3,39)$

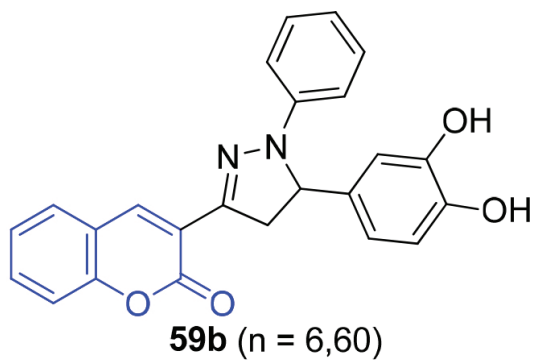<smiles>COc1ccc(-c2c(C)c3ccc(OCc4cn(-c5ccc(C)cc5)nn4)cc3oc2=O)cc1</smiles>

Figura 14. Cumarinas antioxidantes da classe das cumarina-oxadiazóis (56-58), padrões (59a-b), cumarina de origem natural (60a) e 1,2,3-triazol-cumarina (60b) 
Influenza. Atualmente, o tratamento para doenças virais se estabelece na inibição do crescimento da proliferação do vírus, permanecendo ainda longe do ideal, devido a ausência de fármacos capazes de eliminar o vírus diretamente sem danificar a célula hospedeira. ${ }^{78}$

\section{CUMARINAS ANTI-HIV}

A AIDS (Síndrome da Imunodeficiência Adquirida), causada pelo HIV, se espalhou rapidamente através da população humana, desde o seu primeiro relato em $1981 .{ }^{79}$ A AIDS destrói o sistema imune ${ }^{80} \mathrm{e}$ de acordo com a UNAIDS, programa das Nações Unidas sobre HIV/ AIDS, em torno de 36,7 milhões de pessoas no mundo viviam com o vírus HIV até o fim de $2016 .{ }^{81}$ Atualmente, a descoberta de novas estratégias para o tratamento do HIV é um grande desafio para os cientistas devido ao desenvolvimento de resistência aos fármacos disponíveis e toxicidade a eles associada.

Kudo e colaboradores descreveram um produto natural proveniente da casca do caule de Calophyllum Brasiliense, caracterizado como uma cumarina tricíclica com atividade antiviral. O composto 61 (Figura 15) inibiu a replicação do HIV-1 em células infectadas de forma aguda e crônica através da supressão de NF-kB. Os autores utilizaram o modelo de infecção crônica e latente do HIV-1 em células U1, uma linhagem celular latente infectada com HIV-1 cuja replicação ativa do HIV-1 pode ser induzida com PMA e TNF- $\alpha$. O composto $\mathbf{6 1}$ foi capaz de suprimir a replicação viral em células infectadas U1 (PMA) e U1 (TNF- $\alpha$ ) com CE s0 $_{50}$ de 3,48 e 4,32 $\mu \mathrm{M}$, repectivamente. Este composto também foi capaz de suprimir a replicação viral em células Molt-4, infectadas com o virus do HIV-1, com $\mathrm{CE}_{50}$ de $3,41 \mu \mathrm{M}$, demonstrando potencial como composto protótipo para o desenvolvimento de novos agentes anti HIV-1. ${ }^{82}$

Novos compostos planejados pela combinação de cumarinas com hidrazidas foram sintetizados com o objetivo de identificar novos inibidores de HIV-Integrase (HIV-IN). Os compostos foram avaliados in vitro frente a HIV-IN utilizando o ácido chicórico $(\mathbf{6 2 c})$ como padrão (Figura 15). Os compostos com substituintes $-\mathrm{Br}$ ou - $\mathrm{Cl}$ no anel cumarínico e somente o substituinte - $\mathrm{OH}$ no anel fenila, apresentaram os melhores resultados in vitro: 62a (94\% de inibição da HIV-IN a $20 \mu \mathrm{M} \mathrm{e} \mathrm{CI}_{50}$ de $14 \mathrm{nM}$ ) e $\mathbf{6 2 b}$ (95\% de inibição da HIV-IN a $20 \mu \mathrm{M} \mathrm{e} \mathrm{CI}_{50}$ de $13 \mathrm{nM}$ ), com valores de $\mathrm{CI}_{50}$ comparáveis ao ácido chicórico $\left(62 \mathrm{c}, \mathrm{CI}_{50}=10 \mathrm{nM}\right)$. Em geral, observou-se que a presença do substituinte $-\mathrm{Cl}$ no anel fenila ou no anel cumarínico resultou em boa atividade anti-HIV-1 IN. O maior impacto foi observado com a substituição no anel fenila, o que sugere que esta subunidade interage com o íon metálico presente no sítio ativo da enzima. Ademais, a citotoxicidade de todos compostos foi avaliada em células HeLa e os compostos apresentaram baixo, ou nenhum, nível de toxicidade. ${ }^{83}$

Uma série de híbridos de cumarinas-AZT (63 e 64) foram avaliados como inibidores com potencial ação dual sobre a transcriptase reversa (RT) e HIV-1 protease (PR) (Figura 15). ${ }^{84}$ Os ligantes 63a-e (Figura 15) exibiram promissoras atividades inibitórias para HIV-1 PR (56$64 \%$ a $50 \mu \mathrm{M}$ ) com $\mathrm{CI}_{50}$ variando entre 21-29 $\mu \mathrm{M}$ (Tabela 1). Os ligantes 63a e 63b apresentaram valores de porcentagem de inibição da HIV-1 RT comparáveis ao AZT a $50 \mu \mathrm{M}$ (63a - 92\%; 63b - 94\%; AZT - 95\%). Os análogos 64a-e (Figura 15) foram avaliados para a inibição de HIV-1 PR e HIV RT, e exibiram boa eficácia de inibição para HIV-1 PR (52-60\% à $50 \mu \mathrm{M})$ e valores de $\mathrm{CI}_{50}$ na faixa de 22$35 \mu \mathrm{M}$. Já frente à HIV-1 RT, as cumarinas 64a-e exibiram até $99 \%$ de inibição a $50 \mu \mathrm{M}$ e os resultados demonstraram que a introdução do grupo $N$-benzil (64a-e) se mostrou um importante grupo para o aumento da potência inibitória frente a HIV-1 RT. Estes resultados indicam o potencial destes ligantes como protótipos de inibidores com ação dual para HIV-1 PR e RT. ${ }^{84}$

Novos derivados de cumarinas ariladas, obtidos pela reação de acoplamento cruzado de Suzuki-Miyaura, foram avaliados para atividade inibitória anti-HIV in vitro em células humanas. Os compostos 65 e 66 (Figura 16) inibiram a replicação de HIV-1 em cultura celular com $\mathrm{CI}_{50}$ de $12,4 \mu \mathrm{M}$ e $33,1 \mu \mathrm{M}$ com $\mathrm{CC}_{50}$ de $39,1 \mu \mathrm{M}$ e 154,0 $\mu \mathrm{M}$ respectivamente, resultando em um índice de seletividade de 3 e 5 (Figura 15). A presença do grupo metila nas posições 3 e 5 dos grupos fenilas conectados ao anel cumarínico em C-6 e C-7 (65) ou o grupo metila na posição 3 do grupo fenila em C-7, combinado com o grupo triflato em C-6 do anel cumarínico (66), são essenciais para o aumento da atividade anti-HIV,${ }^{85}$ caracterizando de forma marcante um efeito do grupo metila sobre as atividades. ${ }^{86}$

\section{Cumarinas Anti-HCV}

Hepatite é uma doença infecciosa grave que afeta principalmente<smiles>C/C=C(\C)C(=O)c1c(OC)c2c(c3c(CCC)cc(=O)oc13)OC(C)(C)C=C2</smiles>

61<smiles>[R]c1cc([R2])c2oc(=O)c(CNCc3cn([C@H]4CCO[C@H]4CO)nn3)cc2c1</smiles><smiles>O=C(NNC(=O)c1cc2cc(Br)ccc2oc1=O)c1ccccc1</smiles>

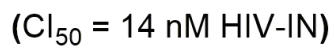<smiles>CN(CC#N)C(=O)c1cc2cc(Cl)ccc2oc1=O</smiles>

$62 b$<smiles>O=C(/C=C/c1ccc(O)c(O)c1)OC(OC(=O)/C=C/c1ccc(O)c(O)c1)C(C(=O)O)C(=O)O</smiles>

62c $\left(\mathrm{Cl}_{50}=10 \mathrm{nM} \mathrm{HIV}-\mathrm{IN}\right)$ $\left(\mathrm{Cl}_{50}=13 \mathrm{nM} \mathrm{HIV-IN}\right)$<smiles>[R]c1cc([R2])c2oc(=O)c(CI)cc2c1</smiles><smiles>Cc1cn([C@H]2C[C@H](n3cc(CNCC(=O)I)nn3)[C@H](CO)O2)c(=O)[nH]c1=O</smiles>

Figura 15. Exemplos de cumarinas com atividade anti-HIV 
Tabela 1. Percentual de inibição das enzimas HIV-1 PR e HIV-1 RT e valores de $\mathrm{CI}_{50}$ para os ligantes 63a-e e 64a-e

\begin{tabular}{|c|c|c|c|c|c|c|}
\hline \multirow[t]{2}{*}{ Composto } & \multirow[t]{2}{*}{$\mathrm{R}_{1}$} & \multirow[t]{2}{*}{$\mathrm{R}_{2}$} & \multicolumn{2}{|c|}{ HIV-1 PR } & \multicolumn{2}{|c|}{ HIV-1 RT } \\
\hline & & & $\%$ de inibição ${ }^{a}$ & $\mathrm{CI}_{50}(\mu \mathrm{M})$ & $\%$ de inibiçãoa & $\mathrm{CI}_{50}(\mu \mathrm{M})$ \\
\hline $63 a$ & $\mathrm{H}$ & $\mathrm{H}$ & 61 & 27,1 & 92 & 5,6 \\
\hline $63 \mathrm{~b}$ & $\mathrm{Br}$ & $\mathrm{H}$ & 57 & 28,9 & 94 & 6,1 \\
\hline $63 \mathrm{c}$ & $\mathrm{H}$ & $\mathrm{OMe}$ & 64 & 21,6 & 29 & 106,4 \\
\hline 63d & $\mathrm{H}$ & OEt & 62 & 23,4 & 21 & 114,0 \\
\hline $63 \mathrm{e}$ & $\mathrm{Cl}$ & $\mathrm{H}$ & 56 & 24,8 & 24 & 101,6 \\
\hline $64 a$ & $\mathrm{H}$ & $\mathrm{H}$ & 52 & 35,1 & 96 & 3,4 \\
\hline $64 \mathrm{~b}$ & $\mathrm{Br}$ & $\mathrm{H}$ & 52 & 32,0 & 94 & 4,2 \\
\hline $64 c$ & $\mathrm{H}$ & $\mathrm{OMe}$ & 60 & 22,7 & 97 & 2,9 \\
\hline $64 d$ & $\mathrm{H}$ & OEt & 58 & 27,3 & 97 & 2,9 \\
\hline $64 \mathrm{e}$ & $\mathrm{Cl}$ & $\mathrm{H}$ & 58 & 29,6 & 99 & 3,7 \\
\hline
\end{tabular}

${ }^{a}$ Percentual de inibição a $50 \mu \mathrm{M}$

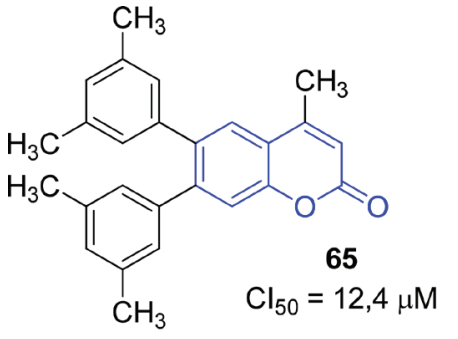<smiles>Cc1cccc(-c2cc3oc(=O)cc(C)c3cc2O)c1</smiles>

Figura 16. Exemplos de cumarinas com atividade anti-HIV

o fígado, causando carcinoma hepatocelular e sendo uma das principais causas de morte no mundo. Aproximadamente 3,5\% da população mundial (200 milhões de pessoas) sofre com doença hepática progressiva causada pelo $\mathrm{HCV}$, resultando em cerca de 100.000 mortes por ano. ${ }^{87-88}$

A hibridação de cumarinas com benzimidazóis pelo uso de um conector tio-metileno originaram compostos com atividade antiviral contra HCV (Figura 17). Os compostos 67 e 68 inibiram a replicação de $\mathrm{HCV}$ com valores de $\mathrm{CE}_{50}$ de 3,4 $\mu \mathrm{M}$ e $4,1 \mu \mathrm{M}$ respectivamente, sendo que 68 inibiu a replicação de RNA do HCV em 90 e 99\% em concentrações de 5 e $16 \mu \mathrm{M}$ respectivamente. O estudo da REA mostrou que a introdução de bromo no núcleo cumarínico aumentou a seletividade em 2,9 vezes e a inibição do $\mathrm{HCV}$ em 6,7 vezes, enquanto a presença de D-glicose no núcleo benzimidazol resultou em aumento de 4,8 vezes na atividade anti-HCV. ${ }^{89}$

Novos compostos híbridos de ribofuranosídeos cumarina-purina (69a-c) com atividade anti-HCV foram desenvolvidos e se mostraram eficientes inibidores da replicação do HCV subgenômico com valores de $\mathrm{CE}_{50}$ de 6,6, 5,5 e 5,9 $\mu \mathrm{M}$, respectivamente. O estudo da REA demonstrou que a presença do núcleo cumarínico nos compostos híbridos era essencial e a presença da subunidade ribofuranose levava ao aumento da inibição do HCV. Além disso, a manutenção de grupos $-\mathrm{OH}$ na ribofuranose levou a redução da citotoxicidade. ${ }^{90}$

\section{Cumarinas Anti-Influenza}

Influenza é uma doença infecciosa que ocorre sazonalmente em proporções epidêmicas ou pandêmicas e ocorre predominantemente no inverno, resultando em milhões de casos graves e muitas mortes todo ano. ${ }^{91}$ Influenza A (H1N1) é um dos subtipos de Influenza e configura-se como a principal causa de influenza sazonal ou pandêmica em todo o mundo. Os vírus influenza estão em constante mudança devido a mutação, dando origem a novas cepas que podem infectar pessoas anteriormente imunes a cepas pré-existentes. ${ }^{92}$ Devido à capacidade de o vírus influenza desenvolver resistência a fármacos existentes, ${ }^{93} \mathrm{o}$ desenvolvimento de novos tipos de fármacos com atividade inibitória contra o vírus influenza se faz necessária.

Khomenko e colaboradores descobriram um composto cumarínico promissor contendo a subunidade monoterpenoide com atividade anti-influenza. O composto $\mathbf{7 0}$ (Figura 18) demonstrou promissora atividade anti-influenza $\left(\mathrm{CI}_{50}=36 \mu \mathrm{M}\right)$, afetando culturas de células infectadas principalmente nos estágios iniciais de reprodução viral (1-2 h da infecção), baixa citotoxicidade $\left(\mathrm{CC}_{50}=982 \mu \mathrm{M}\right)$ e uma síntese acessível. Apesar de não confirmado, o mecanismo proposto por ensaios in silico indicou a hemaglutinina viral como possível alvo. A REA mostrou a importância da subunidade bicíclica pirano para o aumento do índice de seletividade, assim como os substituintes no núcleo cumarínico com a configuração absoluta do monoterpeno. ${ }^{94}$

O derivado cumarínico 71 (Figura 18), isolado do extrato de Sarcandra glabra (medicina tradicional chinesa), apresentou um amplo espetro de atividade contra o vírus influenza e valores de $\mathrm{CI}_{50}$<smiles>[R]c1ccc2c(c1)nc(SCc1cc3cc(Br)ccc3oc1=O)n2[R]</smiles>

67: $R_{1}=F ; \quad R_{2}=H ; C E_{50}=3,4 \mu M$

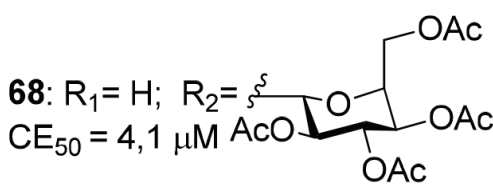

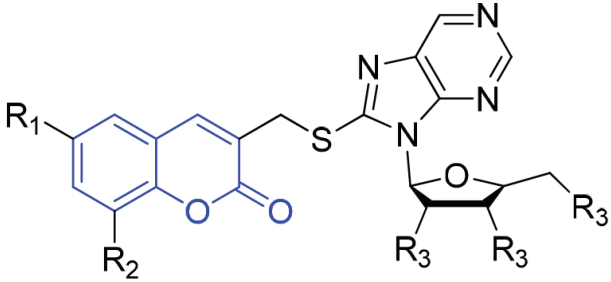

69a: $R_{1}=H ; \quad R_{2}=H ; R_{3}=O A c ; E_{50}=6,6 \mu M$

69b: $\mathrm{R}_{1}=\mathrm{H} ; \quad \mathrm{R}_{2}=\mathrm{H} ; \mathrm{R}_{3}=\mathrm{OH} ; \mathrm{CE}_{50}=5,5 \mu \mathrm{M}$

69c: $\mathrm{R}_{1}=\mathrm{Br} ; \mathrm{R}_{2}=\mathrm{Br} ; \mathrm{R}_{3}=\mathrm{OH} ; \mathrm{CE}_{50}=5,9 \mu \mathrm{M}$ 
<smiles>CC1(C)[C@@H]2C[C@@H]1CC=C2COc1ccc2c3c(c(=O)oc2c1)CCC3</smiles>

70

$\mathrm{Cl}_{50}=36 \mu \mathrm{M}$<smiles>COc1cc2ccc(=O)oc2c(OC)c1OC1OC(CO)C(O)C(O)C1O</smiles>

eleuthe roside $B 1$

Figura 18. Cumarinas com atividade anti-H1N1

entre 166-325 $\mu \mathrm{M}$ in vitro. A REA mostrou que a presença do grupo glicosídico na posição C-7 e a substituição de C-6 e C-8 por grupos metoxilas na estrutura da cumarina é indispensável. ${ }^{95}$

\section{COMPOSTOS CUMARÍNICOS ANTIBACTERIANOS}

As doenças bacterianas afetam a humanidade há séculos e seu controle ainda gera grande preocupação. Atualmente a resistência bacteriana aos antibióticos tem aumentando e o surgimento de cepas multirresistentes é um grande problema de saúde pública em todo o mundo. Embora novos compostos bactericidas estejam sendo descritos na literatura, as doenças causadas por bactérias têm sido a principal causa de morte, principalmente em países subdesenvolvidos e/ou infectados pelo vírus da imunodeficiência humana - HIV. Muitos compostos cumarínicos, naturais e sintéticos tem sido estudados como potentes agentes antibacterianos. ${ }^{96 \mathrm{a}-\mathrm{d}}$ As bactérias atuam patogenicamente através de toxinas, substâncias capazes de causar danos a tecidos. Essas toxinas são classificadas em dois tipos: endotoxinas, secretadas exclusivamente por bactérias Gram negativas, e exotoxinas, que podem ser produzidas por bactérias Gram-positivas e Gram-negativas. ${ }^{97 a-b}$

Uma série de compostos híbridos de cumarina-chalcona com diferentes padrões de substituição foram planejados e sintetizados por Vazquez-Rodriguez e colaboradores (Figura 19). Sua atividade contra bactérias patogênicas humanas (E. coli, S. aureus e P. aeruginosa) e diferentes espécies do gênero Tenacibaculum foram testadas, avaliando suas Concentrações Inibitórias Mínimas (CIM), tendo o enrofloxacino como padrão. Os compostos não foram ativos contra bactérias patogênicas humanas e contra as espécies Tenacibaculum, sendo altamente seletivos e apresentaram alta atividade antibacteriana contra T. maritimum. As substâncias que não possuiam um grupo amino nas posições $R_{3}$ ou $R_{4}$ não foram ativas, mostrando que a presença de um grupo amino na subunidade benzoílica (compostos 72a-h) parece ser uma substituição chave para a atividade de compostos contra T. maritimum (Cepa LL01 8.3.1 - CIM = 0,1-3,9 $\mu \mathrm{M}$; Enrofloxacino - CIM = $2 \mu \mathrm{M})$. Substituições no núcleo da cumarina na posição 8 $\left(\mathrm{R}_{2}\right)$ ou $6\left(\mathrm{R}_{1}\right)$ também desempenharam um papel fundamental em suas atividades, indicando que substituições na posição 8 (72a-b; 72d-e) aumentam sua atividade ( $\mathrm{CIM}=0,5 \mu \mathrm{M} ; 0,2 \mu \mathrm{M} ; 3,9 \mu \mathrm{M}$ e $0,1 \mu \mathrm{M})$, enquanto a substituição na posição 6 (72c e 72f) diminui a atividade antibacteriana de T. maritimum $(\mathrm{CIM}>100 \mu \mathrm{M}) .^{98}$

O Staphylococcus aureus resistente à meticilina (SARM) representa um sério desafio terapêutico clínico atualmente para o desenvolvimento de novos fármacos. As cumarinas naturais têm diversas bioatividades e potenciais de efeitos sobre bactérias resistentes. Zuo e colaboradores avaliaram as atividades antibacterianas in vitro de quatro cumarinas naturais, 5-geraniloxi-7metoxicumarina (73), artanina (74), isopimpinelina (75) e Fellopterina (76), de extratos de Zanthoxylum nitidum (Roxb.) DC. (Rutaceae), dando enfoque em seu potencial de restauração na atividade de agentes antibacterianos convencionais contra cepas clínicas de SARM (Figura 19). As cumarinas $\mathbf{7 3}$ a $\mathbf{7 6}$ apresentaram inibição promissora
A<smiles>[R]c1cc([R2])c2oc(=O)c(C(=O)c3ccc([R])c([R])c3)cc2c1</smiles>

B<smiles>COc1cc(OC/C=C(\C)CCC=C(C)C)c2ccc(=O)oc2c1</smiles>
73

5-geraniloxi-7-metoxicumarina<smiles>COc1cc(OC)c2ccc(=O)oc2c1OCC(C)=C(C)C</smiles>

72a: $R_{1}=R_{3}=H ; R_{2}=O M e ; R_{4}=N_{2} ; C I M=0,5 \mu M$

72b: $R_{1}=R_{3}=H ; R_{2}=$ OEt; $R_{4}=N_{2} ; C I M=0,2 \mu M$

72c: $R_{1}=\mathrm{Br} ; \mathrm{R}_{2}=\mathrm{R}_{3}=\mathrm{H} ; \mathrm{R}_{4}=\mathrm{NH}_{2} ; \mathrm{CIM}>100 \mu \mathrm{M}$

72d R $\mathrm{R}_{1}=\mathrm{R}_{4}=\mathrm{H} ; \mathrm{R}_{2}=\mathrm{OMe} ; \mathrm{R}_{3}=\mathrm{NH}_{2} ; \mathrm{CIM}=3,9 \mu \mathrm{M}$

72e: $R_{1}=R_{4}=H ; R_{2}=$ OEt; $R_{3}=N_{2} ; C I M=0,1 \mu M$

72f: $R_{1}=B r ; R_{2}=R_{4}=H ; R_{3}=N_{2} ; C I M>100 \mu M$<smiles></smiles>

Isopimpinelina

73-76; CIM contra SARM $=8-64 \mu \mathrm{g} \mathrm{ml}^{-1}$

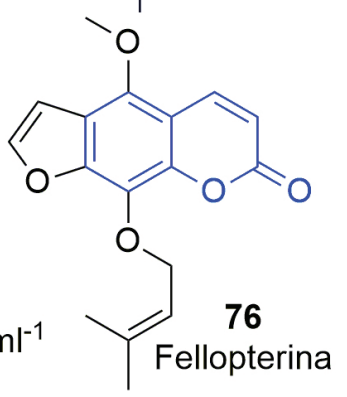

Figura 19. Cumarinas híbridas de chalconas com atividade antibacteriana contra T. Maritimum (A); Cumarinas naturais com atividade frente as infecções $\operatorname{por} \operatorname{SARM}(B)$ 
contra SARM, com CIMs de 8-64 $\mu \mathrm{g} \mathrm{ml}^{-1}$. Adicionalmente, também mostraram diferentes graus de sinergismo com um total de oito agentes antibacterianos convencionais e contra dez cepas clínicas de SARM. As cumarinas apresentaram altos efeitos potencializadores dos agentes antibacterianos contra Staphylococcus aureus resistente a múltiplos fármacos. O efeito de reversão da resistência justifica a investigação farmacológica na terapia combinatória para combater as infecções por SARM. ${ }^{99}$

Derivados cumarínicos e 1,2,3-triazóis são descritos como potentes antibacterianos, ${ }^{100 a-b}$ estas subunidades combinadas podem oferecer algumas vantagens, como a superação da resistência aos medicamentos que já estão em uso clínico, e na melhoria da sua potência. Recentemente López-Rojas e colaboradores também sintetizaram cumarino-triazóis com atividades antibacterianas promissoras. O cumarino-triazol com melhor atividade antibacteriana foi o composto 77 (figura 20), que apresentou CIM = 130,7 $\mu \mathrm{M}$ frente a espécie Enterococcus faecalis, o padrão utilizado nos testes foi o cloranfenicol que aprensenta $\mathrm{CIM}=15,5 \mu \mathrm{M}$ frente a E. faecalis. ${ }^{101}$

Uma nova quimioteca de derivados cumarínicos foi sintetizada através da reação multicomponete de Ugi e avaliada quanto à atividade antibacteriana in vitro em bactérias gram-positivas e gram-negativas. Duas cepas Gram-negativas Klebsiella pneumoniae e Pseudomonas aeruginosa, e duas cepas Gram-positivas Streptococcus aureus e Staphylococcus epidermidis foram utilizadas no rastreamento dos compostos sintetizados. A cefepima foi usada como antibiótico padrão contra todos os organismos usados na avaliação dos valores de CIM [208 $\mu \mathrm{M}]$. Os compostos com melhores valores de CIM foram 78a $\left(0,018 \mu \mathrm{M} \mathrm{ml}^{-1}\right)$ frente a $S$. aureus (cefepima $\left.0,008 \mu \mathrm{M} \mathrm{ml}^{-1}\right)$ e $\mathbf{7 8 b}$ $\left(0,049 \mu \mathrm{M} \mathrm{ml}^{-1}\right)$ frente a $P$. aeruginosa (cefepima $\left.0,027 \mu \mathrm{M} \mathrm{ml}^{-1}\right) .{ }^{102}$

\section{COMPOSTOS CUMARÍNICOS ANTIFÚNGICOS}

O aumento da incidência de infecções fúngicas, e resistência aos fármacos atuais, evidencia a necessidade de novos tratamentos antifúngicos. Consequentemente, a mortalidade e o custo associado aos cuidados médicos para infecções fúngicas estão aumentando constantemente. Além da toxicidade dos medicamentos atualmente utilizados, existem outras desvantagens envolvendo o espectro de atuação, distribuição tecidual, penetração no sistema nervoso central e alto custo, limitando assim o número de antifúngicos efetivos. Adicionalmente, muitos desses fármacos produzem infecção recorrente, pois são fungistáticos e não fungicidas. Diante desse cenário, há uma necessidade urgente do desenvolvimento de novos compostos antifúngicos. ${ }^{103}$

Complexos metálicos de $\mathrm{Co}(\mathrm{II}), \mathrm{Ni}(\mathrm{II})$ e $\mathrm{Cu}(\mathrm{II})$ foram sintetizados a partir de iminas derivadas de 6-formil-7,8-dihidroxi-4metilcumarina com o-metilanilina ou 3-trifluoranilina (Figura 21). Os compostos foram avaliados quanto à sua atividade antifúngica frente a Candida, Aspergillus niger e Rhizopus. Os complexos cumarínicos de $\mathrm{Cu}$ (II) 79a-b a uma concentração de $200 \mu \mathrm{g} \mathrm{ml}^{-1}$, demostraram halo de inibição de 11, 15 e $13 \mathrm{~mm}$, respectivamente para as cepas citadas acima, muito semelhante ao controle positivo Fluconazol (13, 16 e $14 \mathrm{~mm}$ ). Os resultados concluíram que os complexos de cobre são bons antifúgicos frente às cepas testadas. ${ }^{104}$

Uma quimioteca de novos análogos de pirano-cumarinas, descritos por Zhang e colaboradores, foram avaliadas contra os fungos Botrytis cinérea, Colletotrichum copsica, Alternaria solani, Gibberella zeae e Rhizoctorzia solani. Os resultados indicaram que alguns dos compostos tinham atividades antifúngicas potentes em uma concentração inferior a 50 ppm. Para os compostos 80a-c (Figura 21), os valores de $\mathrm{CE}_{50}$ contra Botrytis cinerea foram tão baixos quanto $0,14,0,082$ e $0,091 \mu \mathrm{M}$, respectivamente, o que é melhor do que o fungicida comumente utilizado Azoxistrobina $(0,158$ $\mu \mathrm{M})$. Os compostos 80a (57\%) e 80b (55\%), a 50 ppm, também mostraram controle mais efetivo que a Azoxistrobina (44\%) contra Colletotrichum capsica. ${ }^{105}$

Fungos endófitos de mangues marinhos estão entre as fontes mais produtivas de produtos naturais estruturalmente incomuns e biologicamente ativos. ${ }^{106 a-c}$ Aspergillus clavatus é geralmente encontrado como fungo saprófito, que é gerado na natureza,
A<smiles>CCn1cc(CNc2cc(=O)oc3ccccc23)nn1</smiles>

77

$\mathrm{CIM}=130 \mu \mathrm{M}$ (Enterococcus faecalis)
B<smiles>[R][R]1ccccc1C(NC(=O)c1cc2ccccc2oc1=O)C(=O)NC1CCCCC1</smiles>

78a: $\mathrm{R}=2-\mathrm{NO}_{2} ; \mathrm{CIM}=0,018 \mu \mathrm{M} \mathrm{ml}^{-1}$ (S. aureous)

78b: $\mathrm{R}=4-\mathrm{NO}_{2} ; \mathrm{CIM}=0,049 \mu \mathrm{M} \mathrm{ml}^{-1}$ (P. aeruginosa

Figura 20. Cumarinas-triazólicas com atividade antibacteriana frente a Enterococcus faecalis (A); Cumarinas obtidas pela reação pentacomponente de Ugi com atividade antibacteriana $(B)$

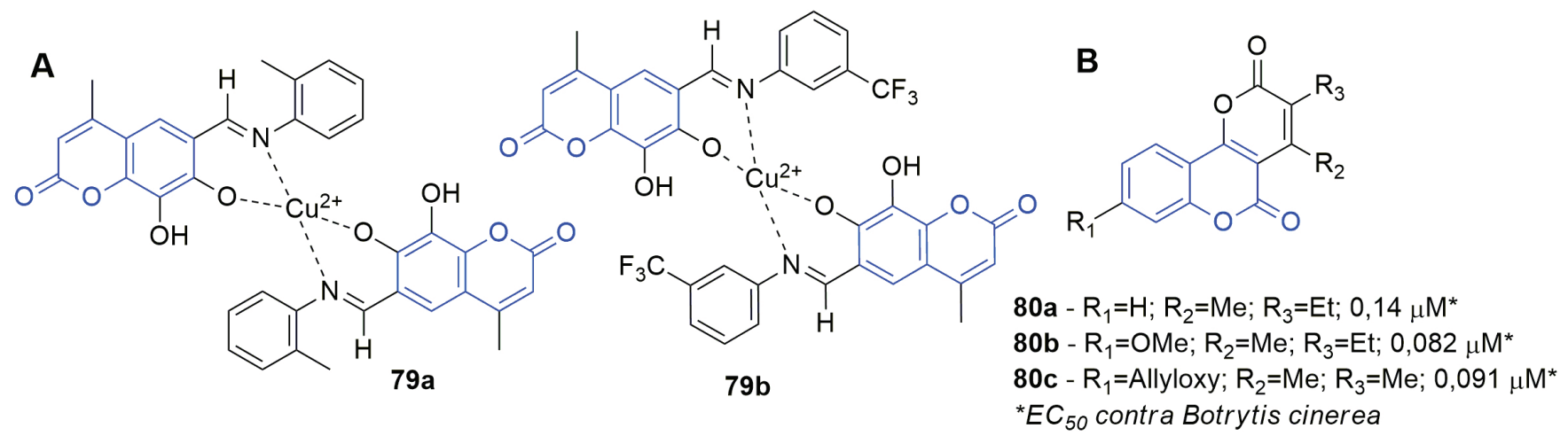

Figura 21. Novos complexos cumarínicos de $\mathrm{Cu}(\mathrm{II})(\mathrm{A})$; e análogos de pirano-coumarinas (B) com atividades antifúngicas 
produzindo micotoxinas e outros metabólitos biologicamente ativos. ${ }^{107 a-e}$ Dois novos derivados da cumarina, 4,4'-dimetoxi-5,5'dimetil-7,7'-oxidicumarina (81) e 7-((3-metilbut-2-en-1-il)oxi-4metoxi-5-metilcumarina (82), juntamente com duas biscumarinas conhecidas, kotanina (83) e orlandina (84; Figura 22), isolados de um fungo Aspergillus clavatus, obtido da raiz de Myoporum bontioides coletada na Península de Leizhou na China, tiveram suas atividades antifúngicas avaliadas. Os compostos 81, 83 e 84 inibiram consideravelmente a cepa de Fusarium oxysporum $(253,81,235,85$ e $252,47 \mu \mathrm{M}$, respectivamente), mostrando maior atividade antifúngica que o controle positivo (triadimefona - 340,43 $\mu \mathrm{M}$ ). ${ }^{108}$

Quatro novos derivados de cumarina-quitosana 85a-d foram sintetizados via reações de condensação de quitosana tiosemicarbazida com derivados de cumarina (Figura 22). Sua atividade antifúngica contra três tipos de higromatologia, Alternaria solani soeauer (A. solani), Fusarium oxysporum f.sp. vasinfectum (F. oxysporum) e Fusarium moniliforme ( $F$. moniliforme) foram testados com taxa de crescimento micelial in vitro a $1,0 \mathrm{mg} \mathrm{ml}^{-1}$. A atividade inibitória da quitosana, tiossemicarbazida-quitosana e derivados da cumarina quitosana (85a-d) contra $F$. oxysporum foi de 9,5, 28,5, 58,1, 69,5, 62,5 e $77,2 \%$, respectivamente. Os derivados de quitosana sintetizados tiveram maior atividade contra os fungos testados em comparação com a quitosana não modificada utilizada como parâmetro. Além disso, a introdução de átomos de halogênio nos derivados da quitosana melhorou a atividade antifúngica. ${ }^{109}$

Uma nova cumarina (86) foi isolada de Artemisia annua (Figura 22) e avaliada contra Fusarium oxysporum, Fusarium solani e Cylindrocarpon destrutans. O composto $\mathbf{8 6}$ inibiu todas as cepas fúngicas com valores de CIM de 152,2, 106,6 e 60,9 $\mu \mathrm{M}$, respectivamente, o que comparado ao controle positivo (hymexazol $-131,9 ; 420,5 ; 262,8 \mu \mathrm{M})$ representa potente atividade antifúngica. ${ }^{110}$

\section{COMPOSTOS CUMARÍNICOS ANTIDIABÉTICOS}

Diabetes é uma doença metabólica crônica que ocorre quando o pâncreas não produz insulina suficiente ou quando o corpo não pode efetivamente usar a insulina produzida no controle da glicemia. ${ }^{111} \mathrm{O}$ aumento do nível de açúcar no sangue, hiperglicemia, é um efeito comum da diabetes e pode causar sérios danos como: cegueira, insuficiência renal, ataques cardíacos, acidente vascular cerebral e amputação de membros inferiores. ${ }^{112}$ A diabetes tipo 1 é caracterizada por uma produção insuficiente, ou nenhuma, de insulina e requer a administração diária de insulina. A diabetes do tipo 2 é a mais comum e geralmente está associada a um excesso de peso corporal, ocorre quando o corpo torna-se resistente à insulina ou não a produz suficientemente. Pacientes com diabetes tipo 2 podem ser tratados com hipoglecimiantes orais e estes apresentam efeitos colaterais como hepatotoxicidade, dor abdominal, diarréia, flatulências e hipoglicemia. Além disso, a resistência a esses medicamentos também foi relatada após o tratamento prolongado. ${ }^{113}$ Portanto, ainda é necessário procurar novos agentes antidiabéticos para evitar ou diminuir os efeitos adversos dos agentes atualmente utilizados.

Inibidores de $\alpha$-glicosidases comprometem a liberação de D-glicose no sangue proveniente de oligossacarídeos e dissacarídeos, o que leva ao atraso da absorção da glicose pelo intestino e, consequentemente, a diminuição dos seus níveis pós-prandiais no sangue. ${ }^{114}$ Estudos realizados por Singha et al descreveram a síntese de cumarinas 7-O-substituídas e as respectivas avaliações in vitro de inibição da $\alpha$-glicosidase e atividade antioxidante (Figura 23). Todas as cumarinas $O$-alquiladas inibiram $\alpha$-glicosidase com valores de $\mathrm{CI}_{50}$ variando entre $41-540 \mu \mathrm{M}$. A alquilação se mostrou importante já que $\mathbf{8 7} \mathbf{a}(7-\mathrm{OH})$ não foi ativa. O composto $\mathbf{8 7 d}$, portador do grupamento benzila na posição 7 , apresentou $\mathrm{CI}_{50}$ igual a $41,9 \mu \mathrm{M}$, comparável ao padrão acarbose, $\mathrm{CI}_{50}=24,6 \mu \mathrm{M}$. Outros compostos apresentando cadeias 7- $O$-alquílicas também tiveram sua atividade otimizada em relação à acarbose. Entretanto, a substituição por grupos acetil, alquil ramificados e alila levou a redução da atividade. ${ }^{115}$

A proteína tirosina fosfatase 1B (PTP1B) desempenha um papel fundamental na regulação da insulina, exercendo um efeito regulatório negativo da via de sinalização de insulina em condições fisiológicas normais. A inibição de PTP1B promove a melhora da ação da insulina e a tolerância glicêmica. ${ }^{116}$ Recentemente Jung e colaboradores investigaram o efeito antidiabético da $\alpha$-metil artoflavanocumarina (88) (Figura 23), uma flavanocumarina natural isolada da espécie Juniperus chinensis, e observaram que este composto era capaz de inibir a PTP1B com valor de $\mathrm{CI}_{50}$ igual a 25,27 $\mu \mathrm{M}$. Através de estudos de cinética enzimática foi evidenciado que o composto $\mathbf{8 8}$ era um inibidor misto com valor de Ki igual a 13,84 $\mu \mathrm{M}$. Estudos in silico demonstraram que $\mathbf{8 8}$ foi capaz de se ligar através do sítio catalítico e alostérico da PTP1B, o que corrobora com o modo
A<smiles>[R]Oc1ccc2c(OC)cc(=O)oc2c1-c1c(O[R])cc(C)c2c(OC)cc(=O)oc12</smiles>

B<smiles>[R]c1cc([R])c2oc(=O)c(/C(C)=N\NC(=S)NC3OC(O)C(O)CC3CO)cc2c1</smiles>

$85 a-\mathrm{R}_{1}=\mathrm{H} ; \mathrm{R}_{2}=\mathrm{H}$

$85 \mathrm{~b}-\mathrm{R}_{1}=\mathrm{Cl} ; \mathrm{R}_{2}=\mathrm{H}$

$85 \mathrm{c}-\mathrm{R}_{1}=\mathrm{Br} ; \mathrm{R}_{2}=\mathrm{H}$

$85 \mathrm{~d}-\mathrm{R}_{1}=\mathrm{Cl} ; \mathrm{R}_{2}=\mathrm{Cl}$

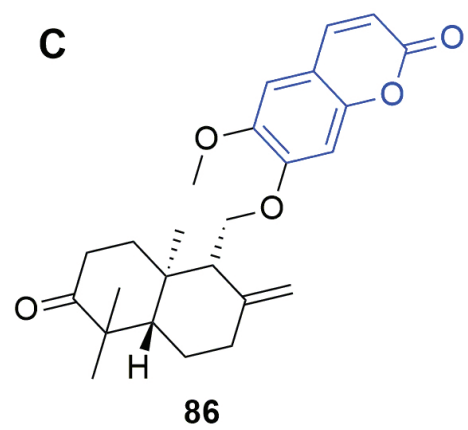

86

Figura 22. Cumarinas isoladas de fungo endofítico de Aspergillus clavatus (A); derivadas de quitosana (B) e extraída de Artemisia annua com atividades antifúngicas $(C)$ 
misto de inibição observado nos estudos cinéticos. Também foi observada ativação da via de sinalização responsável por regular o metabolismo de glicose IRS-1/ PI3K/Akt e ERK1, ocasionada pela diminuição da expressão da PTP1B, com consequentemente aumento da sensibilidade à insulina. ${ }^{117}$

Duas cumarinas (89 e 90) isoladas do caule da Angelica keiskei Koidzumi, uma planta originária do Japão conhecida como rejuvenescedora e antidiabética, também foram avaliadas quanto à sua atividade inibitória da PTP1B (Figura 23). A cumarina 89 demonstrou alta atividade inibitória de PTP1B $\left(\mathrm{CI}_{50}=11,7 \mu \mathrm{M}\right)$, enquanto três cumarinas 90a-c demonstraram atividade inibitória moderada $\left(\mathrm{CI}_{50}=31,19 \mu \mathrm{M} ; 30,31 \mu \mathrm{M}\right.$; e 39,7 $\mu \mathrm{M}$, respectivamente $){ }^{118}$

A perda excessiva de células $\beta$ pancreáticas, principalmente devido à apoptose, é uma das principais características do desenvolvimento de diabetes tanto do tipo 1 quanto do tipo $2 .{ }^{119} \mathrm{~A}$ dafnetina 91 (Figura 23), cumarina de origem natural, foi avaliada in vitro contra o dano induzido por estreptomicina (STZ) em células $\beta$ pancreáticas INS-1 de ratos, através do aumento do estresse oxidativo e da produção de espécies reativas de oxigênio (ROS). O resultado do teste do MTT indicou que a viabilidade das células INS-1 foi significativamente reduzida com a exposição à STZ durante $12 \mathrm{~h}$ por indução à apoptose, em comparação com as células de controle, enquanto as pré-tratadas com dafnetina 91 durante $24 \mathrm{~h}$ apresentaram significativo aumento dessa viabilidade celular. Além de melhora na secreção de insulina estimulada por glicose. Ensaio de Western Blot revelou que a dafnetina 91 poderia suprimir a apoptose através da elevação da regulação da expressão anti-apoptótica da proteína Bcl-2 e da regulação negativa dos níveis pró-apoptóticos de proteína Bax e NF- $\kappa \mathrm{B} .{ }^{120}$

As células adiposas secretam adipocitocinas, que levam à resistência à insulina na diabetes tipo $2 .{ }^{121}$ Desse modo, compostos capazes de aumentar a diferenciação e a lipólise de adipócitos, tem sido utilizados como antidiabéticos. Recentemente, Choi e colaboradores avaliaram os efeitos antidiabéticos e anti-obesidade do composto 92 (Figura 23), isolado de folhas de Peucedanum japonicum Thunb sai, planta originada do Japão. Este composto efetivamente inibiu a diferenciação de adipócitos de uma maneira dose-dependente, além de reduzir significativamente os níveis de triglicerídeos e estimular absorção de glicose em comparação ao controle em células de pré-adipócito 3T3-L1. O composto 92 aumentou significativamente a ativação da proteína quinase ativada por AMP (AMPK), responsável por estimular vias catabólicas e inibir vias anabólicas. Além de reduzir o RNAm e, consequentemente a expressão proteica dos principais fatores de transcrição adipogênicos, como C/EBPa, PPARc e SREBP-1c em células 3T3-L1. Ademais, 92 apresentou atividade inibidora de $\alpha$-glicosidase. Esses resultados indicaram que o composto cumarínico 92 é um potencial agente MTLD natural para diabetes e obesidade. ${ }^{122}$

\section{COMPOSTOS CUMARÍNICOS ANTI-INFLAMATÓRIOS}

A inflamação é uma resposta do organismo contra lesão ou infecção, com o propósito de limitar a propagação do agente prejudicial e promover o reparo de tecidos. Tal processo é mediado por biomoléculas que levam às reações inflamatórias, incluindo: metabólitos de ácido araquidônico, óxido nítrico, bradicinina, citocinas, aminas vasoativas, eicosanóides, quimiocinas, interleucinas e fatores de crescimento. ${ }^{123 a-b}$

O lipopolissacarídeo (LPS) é uma endotoxina proveniente da membrana celular externa de bactérias gram-negativas, conhecido como um importante ativador da resposta imunológica. ${ }^{124}$ Recentemente, novos derivados cumarinícos 7-substituídos (93a-f) foram descritos com atividade anti-inflamatória frente às células RAW 264 estimuladas por LPS (Figura 24). Todos os compostos diminuíram os níveis dos mediadores pró-inflamatórios IL-6 e TNF- $\alpha$. O composto 93b foi o mais ativo, com redução de até 50\% do nível dos mediadores comparado ao LPS. Estudos de REA mostraram que substituintes $\mathrm{R}$ afetam significativamente a atividade anti-inflamatória e que o grupamento metoxila se mostrou melhor que os substituintes halogenados. Estudos in silico mostraram que o composto $\mathbf{9 3 b}$, possivelmente, liga-se ao sítio ativo do fator de transcrição NF- $\mathrm{BB}$, bloqueando esta via de sinalização, o que foi confirmado por análises de ressonância plasmônica de superfície (SPR). Além disso, ensaios de Western blot mostraram a redução da fosforilação de p65 por 93b e também a inibição de algumas espécies à jusante, como iNOS and COX-2. ${ }^{125}$

Ainda com enfoque na modulação de IL-6 e TNF- $\alpha$, uma nova série de derivados fenil-pirazolina-cumarínicos foi planejada e sintetizada por Chen e colaboradores. Alguns derivados foram capazes de reduzir os níveis destas citocinas em células RAW 264 induzidas

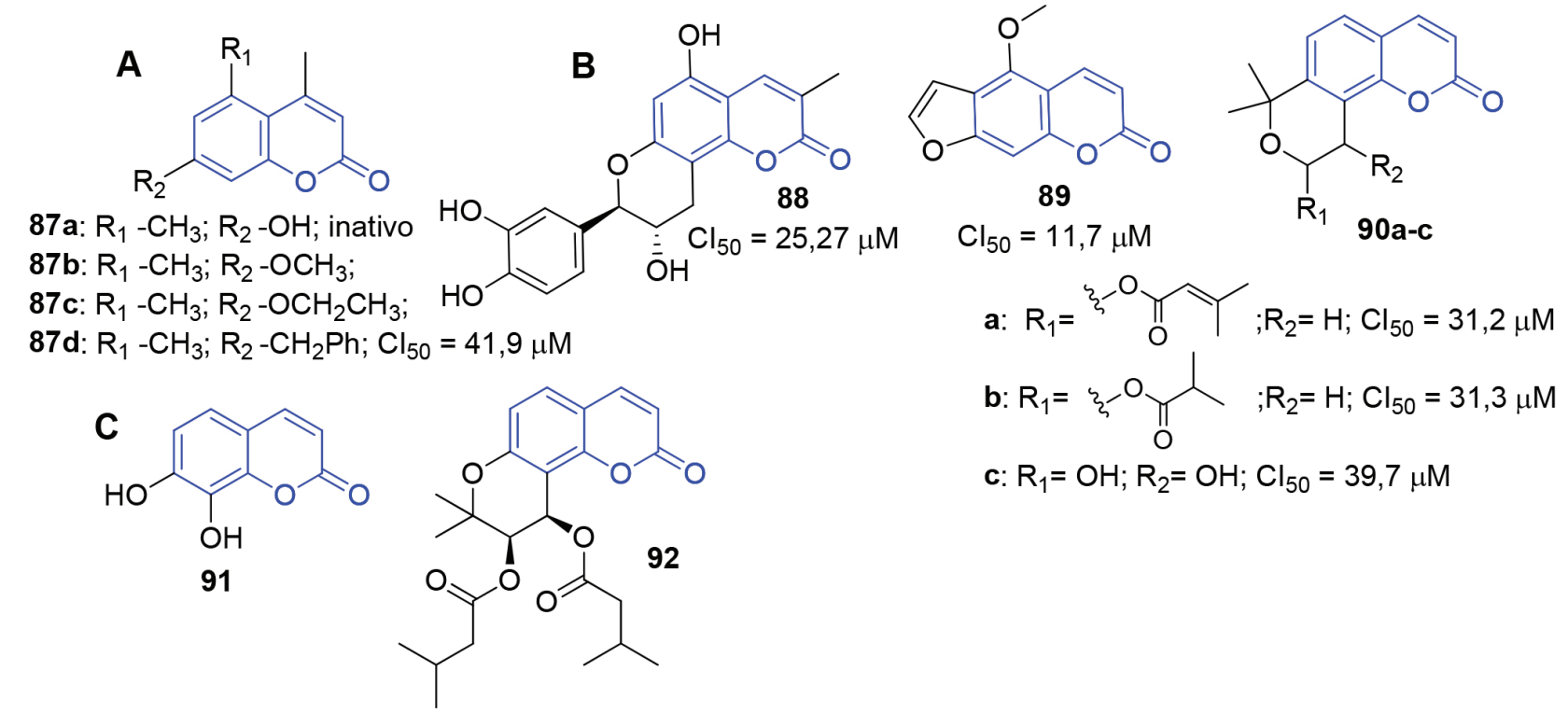

Figura 23. Derivados cumarinicos com atividade antidiabética pela inibição da $\alpha$-glicosidases (A) e proteína tirosina fosfatase $1 B(B)$ e Cumarinas de origem natural com atividade anti-diabética por ação anti-apoptótica e anti-adipogênica (C) 
por LPS. Estudos adicionais com o composto 94 mostraram que este suprime significativamente as expressões de óxido nítrico sintase (iNOS), ciclooxigenase-2 (COX-2) e a produção de IL-6, TNF- $\alpha$ e NO através da via de sinalização NF-kB/MAPK. ${ }^{126}$

Os anti-inflamatórios não esteroidais (AINE's) são os fármacos mais utilizados para o tratamento da inflamação, atuando na supreção da produção de prostaglandinas e tromboxanos através da inibição da enzima COX. ${ }^{127 a-b}$ Os AINE's clássicos inibem as duas isoformas da COX, classificadas como: COX-1, ou constitutiva, e COX-2, ou indutiva. Já os coxibes, fármacos de segunda geração, inibem seletivamente a isoforma COX-2. Acredita-se que as propriedades anti-inflamatórias dos AINES são mediadas através da COX-2 $2^{128} \mathrm{e}$ os efeitos colaterais, como a incidência de lesões gastrointestinais, são oriundos da inibição da COX-1. ${ }^{129}$

Uma série de 3-metil-1-fenilcromeno [4,3-c]pirazol-4(1H)onas foram sintetizadas e avaliadas frente a enzima COX. Entre os compostos desta série 95a-d e $95 \mathbf{f}$ foram identificados como inibidores seletivos da COX-2, com $\mathrm{CI}_{50}$ entre 1,79 e 4,35 $\mu \mathrm{M}$, e índice de seletividade COX-1/COX-2 (SI) de 6,8 à 16,7 (Figura 25). O composto 95b apresentou a maior potência pela COX-2 $\left(\mathrm{CI}_{50}=1,79 \mu \mathrm{M}\right)$, seguido por $95 \mathbf{f}\left(\mathrm{CI}_{50}=2,36 \mu \mathrm{M}\right)$ e $\mathbf{9 5 c}$ $\left(\mathrm{CI}_{50}=2,43 \mu \mathrm{M}\right)$. Os estudos de REA sugeriram que a presença de substituinte retiradores de elétrons no anel $N$-fenila (95b-d e 95f) aumenta a potência e seletividade frente à $\mathrm{COX}-2$, no qual $4-\mathrm{CF}_{3}$ (95b) $>4-\mathrm{F}$ (95f) $>4-\mathrm{Cl}$ (95c) $>4-\mathrm{Br}$ (95d). A avaliação de atividade anti-inflamatória dos compostos foi realizada através do modelo de edema de pata de rato induzido por carragenina $\left(150 \mu \mathrm{mol} \mathrm{kg} \mathrm{kg}^{-1}\right)$ e os resultados mostraram que quatro compostos $(\mathbf{9 5 b}, \mathbf{9 5} \mathrm{c}$ e $95 \mathbf{f})$ possuem atividades anti-inflamatórias significativas, com reduções de 59,9\%; 49,4\%; e 55,6\% do edema, respectivamente, após 5 h (controle positivo celecoxibe, inibição de $51,4 \%) .{ }^{130}$

$\mathrm{O}$ óxido nítrico (NO) é um dos importantes mediadores inflamatórios, sendo secretado por células como macrófagos. ${ }^{131}$ Níveis elevados de NO na inflamação crônica podem resultar em várias doenças, ${ }^{132}$ já que este pode interagir com oxigênio molecular e ânions superóxido para formar EROs que podem modificar várias funções celulares. ${ }^{133}$.

Neste contexto, Lv e colaboradores descreveram o isolamento de dois novos 8-metilbenzo [h]cumarinas (biossíntese proposta passando por uma eletrociclização de 96 para 97; Figura 25), nove novas cumarinas C-8-substituídas (muralatinas) e vinte e duas estruturas análogas já conhecidas das folhas de Murraya alata. Cinco compostos inibiram a produção de óxido nítrico induzida por LPS em macrófagos RAW 264, sendo o composto 98 o mais ativo, com valor de $\mathrm{CI}_{50}$ igual a $6,0 \mu \mathrm{M}$, semelhante ao controle positivo indometacina $(6,3 \mu \mathrm{M}) \cdot{ }^{134}$

De modo semelhante, derivados cumarínicos isolados do caule de $C$. lenis, três inéditos e nove já descritos, foram avaliados quanto sua atividade anti-inflamatória e anti-HIV. Os compostos inibiram significativamente a produção de óxido nítrico (NO) induzida por LPS em macrófagos RAW 264, com valores de $\mathrm{CI}_{50}$ que variam de<smiles>COc1ccc(-c2coc3cc(OCC(=O)n4cc(-c5ccc(C(F)(F)F)cc5)c(-c5cc6ccccc6oc5=O)n4)ccc3c2=O)cc1</smiles>

Figura 24. Derivados cumarinicos com atividade anti-inflamatória atuando na redução dos níveis das citocinas IL-6 e TNF- $\alpha$
93a: $\mathrm{R}=2-\mathrm{OCH}_{3}$
93d: $\mathrm{R}=2-\mathrm{Cl}$
93b: $\mathrm{R}=3-\mathrm{OCH}_{3}$
93e: $R=4-F$
93c: $\mathrm{R}=4-\mathrm{OCH}_{3}$
93f: $R=4-B r$<smiles>[R]c1ccc(-n2nc(C)c3c(=O)oc4ccccc4c32)cc1</smiles><smiles>COC(=O)/C=C\c1c(OC)cc(OC)c2ccc(=O)oc12</smiles><smiles>COc1cc(OC)c2ccc(=O)oc2c1/C=C/C(C)=O</smiles>

95a: $\mathrm{R}=\mathrm{H}$

95b: $\mathrm{R}=4-\mathrm{CF}_{3} ; \mathrm{Cl}_{50}=1,79 \mu \mathrm{M}$

95c: $\mathrm{R}=4-\mathrm{Cl} ; \mathrm{Cl}_{50}=2,36 \mu \mathrm{M}$

95d: $R=4-B r$

95e: $\mathrm{R}=2,5-\left(\mathrm{CH}_{3}\right)_{2}$

95f: $\mathrm{R}=4-\mathrm{F} ; \mathrm{Cl}_{50}=2,36 \mu \mathrm{M}$<smiles>[R]C1c2cc3cc(C(C)(C)C=C)c(=O)oc3c(CC=C(C)C)c2O[C@H]1C(C)(C)O</smiles>

99a; $\mathrm{R}=\mathrm{H} ; \mathrm{Cl}_{50}=0,52 \mu \mathrm{M}$

99b; $\mathrm{R}=\mathrm{OH} \mathrm{Cl}_{50}=1,06 \mu \mathrm{M}$<smiles>[R]c1ccc2nc(NCC(O)COc3ccc4c(C)cc(=O)oc4c3)sc2c1</smiles>

101a: $\mathrm{R}_{1}=6-\mathrm{NO}_{2} ; \mathrm{Cl}_{50}=3,23 \mathrm{nM}$

101b: $\mathrm{R}_{1}=5-\mathrm{Cl}, 6-\mathrm{F} ; \mathrm{Cl}_{50}=6,16 \mathrm{nM}$

101c: $\mathrm{R}_{1}=6-\mathrm{Cl} ; \mathrm{Cl}_{50}=2,79 \mathrm{nM}$

101d: $R_{1}=5,6-d i C l ; 15,50 \mathrm{nM}$

101e: $\mathrm{R}_{1}=6-\mathrm{OMe} ; \mathrm{Cl}_{50}=2,09 \mathrm{nM}$

Figura 25. Derivados cumarinicos com atividade anti-inflamatória. Inibidores seletivos de COX-2 (94a-f), inibidores da produção de NO (95-98) e inibidores de 5-LOX (99-100a-e) 
0,52 a 10,39 $\mu \mathrm{M}$ comparáveis ao padrão hidrocortisona. Além disso, os derivados também exibiram atividade anti-HIV-1 RT com valores de $\mathrm{CE}_{50}$ entre 0,17 a $9,08 \mu \mathrm{M}$. Dentre os derivados estudados, os compostos 99a e 99b (Figura 25) se mostraram os mais potentes tanto para a atividade anti-inflamatória $\left(\mathrm{CI}_{50}\right.$ de $0,52 \mu \mathrm{M}$ e $1,06 \mu \mathrm{M}$, respectivamente) quanto anti-HIV-1 $\mathrm{RT}\left(\mathrm{CE}_{50}\right.$ de 0,29 e $0,17 \mu \mathrm{M}$, respectivamente). ${ }^{135}$

Os leucotrienos são mediadores da inflamação que derivam da oxidação de ácidos graxos polinsaturados através da enzima 5-lipoxigenase (5-LOX) e atuam através da interação com os receptores LTB4, BLT1 e BLT2. ${ }^{136}$

Derivados cumarínicos sintéticos substituídos em C-7, 100 e 101 (Figura 25), foram avaliados para atividade anti-inflamatória e analgésica in vivo, assim como a determinação de suas capacidades de inibição da enzima 5-LOX in vitro. Os compostos 101c e 101e apresentaram $\mathrm{CI}_{50}$ para a inibição da 5-LOX de 2,79 nM e 2,09 nM, respectivamente, demonstrando a importância da presença do mono-substituinte $-\mathrm{Cl}$ em 101c e $-\mathrm{OCH}_{3}$ em 101e na posição $\mathrm{C} 6$ do anel benzotiazol para a atividade anti-inflamatória. Isso pôde ser comparado com 101b $\left(\mathrm{CI}_{50}=6,16 \mathrm{nM}\right)$ e $\mathbf{1 0 1 d}\left(\mathrm{CI}_{50}=15,50 \mathrm{nM}\right)$, que apesar de potentes, mostraram menor potência inibitória comparada com os compostos mono-substituídos 101c e 101e. O estudo cinético in vitro do composto 101e mostrou que esta série de compostos apresdentou uma inibição não competitiva com a enzima 5-LOX. ${ }^{136}$

\section{CONCLUSÃO}

Levando em consideração o número de exemplos expostos neste trabalho de revisão, tanto em termos estruturais como em relação aos alvos terapêuticos, fica evidente a importância do núcleo cumarínico para a Química Medicinal. Neste artigo, focamos apenas em trabalhos com destacada atividade biológica como agentes anticoagulante, anticâncer, anti-neurodegenerativo, antioxidante, antiviral, antidiabético, anti-inflamatório, antibacteriano e antifúngico nos últimos anos. Portanto, esperamos que este trabalho de revisão contribua para o desenvolvimento racional de novos projetos de pesquisa utilizando cumarinas para o tratamento de doenças emergentes.

\section{AGRADECIMENTOS}

Este trabalho foi amparado pela Fundação de Amparo à pesquisa do Estado do Rio de Janeiro (FAPERJ), pelo Conselho Nacional de Desenvolvimento Científico e Tecnológico (CNPq), pela Coordenação de Aperfeiçoamento de Pessoal de Nível Superior (CAPES) e pela UFRRJ.

\section{REFERÊNCIAS}

1. Kostova, I.; Mini-Rev. Med. Chem. 2006, 6, 365.

2. Souza, L. G.; Rennó, M. N.; Figueroa-Villar, J. D.; Chem. Biol. Interact. 2016, 254, 11.

3. Ribeiro, C. V. C.; Kaplan, M. A. C.; Quím. Nova 2002, 25, 533.

4. Hoult, J. R. S.; Paya, M.; Gen. Pharm. 1996, 27, 713.

5. Pereira, T. M.; Franco, D. P.; Vitorio, F.; Kummerle, A. E.; Curr. Top. Med. Chem. 2018, 18, 124.

6. Dewick, P. M.; Medicinal natural products: A biosynthetic approach, 2nd ed.; Wiley \& Sons: New York, 2002; Costa, T. M.; Tavares, L. B. B.; Oliveira, D.; Appl. Microbiol. Biotechnol. 2016, 100, 6571; Yang, S. M.; Shim, G. Y.; Kim, B. G.; Ahn, J. H.; Microb. Cell Fact. 2015, 14, 1.

7. Medina, F. G.; Marrero, J. G.; Macías-Alonso M.; Gonzales, M. C.; Córdova-Guerrero, I.; Garcia, A. G. T.; Osegueda-Robles, S.; Nat. Prod. Rep. 2015, 32, 1472 .
8. Murray, R. D. H.; Nat. Prod. Rep. 1995, 12, 477.

9. Pereira, T. M.; Vitorio, F.; Amaral, R. C.; Zanoni, K. P. S.; Iha, N. Y. M.; Kummerle, A. E.; New J. Chem. 2016, 40, 8846; Symeonidis, T.; Chamilos, M.; Litina, D. J. H.; Kallitsakis, M.; Litinas, K. E. Bioorg. Med.Chem. Lett. 2009, 19, 1139.

10. Peng, X. M.; Damu, G. L. V.; Zhou, C. H.; Curr. Pharm. Des. 2013, 19 , 3884.

11. https://www.accessdata.fda.gov/scripts/cder/daf/index. cfm?event=BasicSearch.process, acessa-da em 04/01/2018. https:// consultas.anvisa.gov.br/\#/medicamentos/q/?substancia=22353, acessado em Janeiro de 2018.

12. Li, J.; Zhang, C. F.; Yang, S. H.; Yang, W. C.; Yang, G. F. A.; Anal. Chem. 2014, 86, 3037.

13. Vitorio, F.; Pereira, T. M.; Castro, R. N.; Guedes, G. P.; Graebin, C. S.; Kummerle, A. E.; New J. Chem. 2015, 39, 2323.

14. Pereira, T. M.; Franco, D. F. P.; Vitório, F.; Amaral, R. C.; Ponzoni, A. C.; Kummerle, A. E. Quim. Nova 2018, 41, 1205.

15. Areas, E. S.; Bronsato, B. J. D. S.; Pereira, T. M.; Guedes, G. P.; Miranda, F. D. S.; Kümmerle, A. E.; da Cruz, A. G. B.; Neves, A. P.; Spectrochimica Acta Part A: Molecular and Biomolecular Spectroscopy 2017, 187, 130; Areas, E. S.; Paiva, J. L. D. A.; Ribeiro, F. V.; Pereira, T. M.; Kummerle, A. E.; Silva, H.; Guedes, G. P.; Nascimento, A. C. C. N.; Miranda, F. D. S; Neves, A. P.; Eur. J. Inorg. Chem. 2019, 2019, 4031.

16. Maruyama, T.; Otagiri, M.; Schulman, S. G.; J. Pharm. 1990, $59,137$.

17. Du, L. P.; Zhang, G. L.; Mei, D.; Eval. Anal. 2008, 8, 576.

18. Wang, H.; Lu, X. M.; Yao, H.; Feng, J. K.; Liu, R.; J. Chem. Ind. Times 2009, 23, 40 .

19. Silverman, R. B.; J. Am. Chem. Soc. 1980, 102, 5421.

20. Montagut-Romans, A.; Boulven, M.; Jacolot, M.; Moebs-Sanchez, S.; Hascoët, C.; Hammed, A. Besse, S.; Lemaire, M.; Benoit, E.; Lattard, V.; Popowycz, F.; Bioorg. Med. Chem. Lett. 2017, 27, 1598.

21. Elg, M.; Gustafsson, D.; Carlsson S.; Thromb. Res. 1999, 94, 187.

22. Roehrig, S.; Straub, A.; Pohlmann, J.; Lampe, T.; Pernerstorfer, J.; Schlemmer, K. H.; Reinemer, P.; Perzborn, E.; J. Med. Chem. 2005, 48, 5900.

23. Frédérick, R.; Charlier, C.; Robert, S.; Wouters, J.; Masereel, B.; Pochet, L.; Bioorg. Med. Chem. Lett. 2006, 16, 2017.

24. Sashidhara, K. V.; Kumar, A.; Kumar, M.; Singh, S.; Jain, M.; Dikshit, M.; Bioorg. Med. Chem. Lett. 2011, 21, 7034.

25. Amin, K. M.; Gawad, N. M. A.; Rahman, D. E. A.; Ashry, M. K. M. E.; Bioorg. Chem. 2014, 52, 31.

26. Lei, L.; Xue,Y,; Liu, Z.; Peng, S.; He, Y.; Zhang, Y.; Fang, R.; Wang, J.; Luo, Z.; Yao, Z.; Zhang, J.; Zhang, G.; Song, H.; Zhang, Y.; Sci. Rep. 2015, 5, 13544.

27. Arora, R. B.; Mathur, C. N.; Brit. J. Pharmacol. 1963, 20, 29.

28. Khalighi-Sigaroodi, F.; Hadjiakhoondi, A.; Shafiee, A.; Daru, J. Pharm. Sci. 2006, 14, 214.

29. Mozaffarian, V.; A Dictionary of Iranian Plant Names. Tehran: Farhange Moaser, 2007.

30. Golfakhrabadi, F.; Abdollahi, M.; Ardakani, M. R.; Saeidnia, S.; Akbarzadeh, T.; Ahmadabadi, A. N.; Ebrahimi, A.; Yousefbeyk, F.; Hassanzadeh, A.; Khanavi, M.; Pharm. Biol. 2014, 52, 1335.

31. Pierce, B. A.; Genetics: A Conceptual Approach, 3rd ed.; W. H. Freeman and Company, New York, 2010.

32. Hanahan, D; Weinberg, R. A.; Cell 2000, 100, 57.

33. Chang, J.-Y.; Hsieh, H.-P.; Chang, C.-Y.; Hsu, K.-S.; Chiang, Y.-F.; Chen, C.-M.; Kuo, C.-C.; Liou, J.-P.; J. Med. Chem. 2006, 49, 6656; Jordan, M. A.; Wilson, L.; Nat. Rev. Cancer 2004, 4, 253.

34. Cao, D.; Liu, Y.; Yan, W.; Wang, C.; Bai, P.; Wang, T.; Tang, M.; Wang, X.; Yang, Z.; Ma, B.; Ma, L.; Lei, L.; Wang, F.; Xu, B.; Zhou, Y.; Yang, T.; Chen, L.; J. Med. Chem. 2016, 59, 5721.

35. Fu, D.-J.; Li, P.; Wu, B.-W.; Cui, X.-X.; Zhao, C.-B.; Zhang S.-Y.; Eur. J. Med. Chem. 2019, 165, 309. 
36.. Cruz, I. N.; Zhang, Y.; Fuente, M. de La.; Schatzlein, A.; Yang, M.; Anal. Biochem. 2013, 438, 107.

37. Wandinger, S. K.; Richter, K.; Buchner, J.; J. Bio. Chem. 2008, 283, 18473.

38. Workman, P.; Curr. Opin. Investig. Drugs 2003, 4, 1410.

39. Yu, X.; Shen, G.; Neckers, L.; Blake, H.; Holzbeierlein, J.; Cronk, B.; Blagg, B. S. J.; J. Am. Chem. Soc. 2005, 127, 12778.

40. Zhao, J.; Zhao, H.; Hall, J. A.; Brown, D.; Brandes, E.; Bazzill, J.; Grogan, P. T.; Subramanian, C.; Vielhauer, G.; Cohenbce, M. S.; Blagg, B. S. J.; Med. Chem. Commun. 2014, 5, 1317.

41. Wei, Q.; Ning, J. Y.; Dai, X.; Gao, Y. D.; Su, L.; Zhao, B. X.; Miao, J. Y.; Eur. J. Med. Chem. 2018, 145, 551.

42. Arrowsmith, C. H.; Bountra, C.; Fish, P. V.; Lee, K.; Schapira, M.; Nat. Rev. Drug Disc. 2012, 11, 384.

43. Dokmanovic, M.; Clarke, C.; Marks, P. A.; Mol. Cancer Res. 2007, 5, 981.

44. Grunstein, M.; Nature 1997, 389, 349.

45. Weichert, W.; Cancer Lett. 2009, 280, 168.

46. Abdizadeh, T.; Kalani, M. R.; Abnous, K.; Tayarani-Najaran , Z.; Khashyarmanesh, B. Z.; Abdizadeh, R.; Ghodsi, R.; Hadizadeh, F.; Eur. J. Med. Chem. 2017, 132, 42.

47. Neri, D.; Supuran, C. T.; Nat. Rev. Drug Discov. 2011, 10, 767. Supuran, C. T.; J. Enzyme Inhib. Med. Chem. 2016, 31, 345.

48. Chiche, J.; Brahimi-Horn, M. C.; Pouyssegur, J.; J. Cell Mol Med. 2010, 14, 771; Brahimi-Horn, M. C.; Pouyssegur, J.; Essays Biochemistry 2007, 43, 165; Swietach, P.; Vaughan-Jones, R. D.; Harris, A. L.; Cancer Metastasis Rev. 2007, 26, 299.

49. Pastorek, J.; Zatovicova, M.; Pastorekova, S.; Curr. Pharm. Des. 2008, 14, 685; Sowa, T.; Menju, T.; Chen-Yoshikawa, T. F.; Takahashi, K.; Nishikawa, S.; Nakanishi, T.; Shikuma, K.; Motoyama, H.; Hijiya, K.; Aoyama, A.; Sato, T.; Sonobe, M.; Harada, H.; Date, H.; Cancer Med. 2017, 6, 288; Lou, Y.; McDonald. P. C.; Oloumi A.; Chia, S.; Ostlund, C.; Ahmadi, A.; Kyle, A.; auf dem Keller, U.; Leung, S.; Huntsman, D.; Clarke, B.; Sutherland, B. W.; Waterhouse, D.; Bally, M.; Roskelley, C.; Overall, C. M.; Minchinton, A.; Pacchiano, F.; Carta, F.; Scozzafava, A.; Touisni, N.; Winum, J. Y.; Supuran, C. T.; Dedhar, S.; Cancer Res. 2011, 71, 3364; Grandane, A.; Tanc, M.; Mannelli, L. Di C.; Carta, F.; Ghelardini, C.; Žalubovskis, R.; Supuran, C. T.; J. Med. Chem. 2015, 58,3975 .

50. Bonardi, A.; Falsini, M.; Catarzi, D.; Varano, F.; Mannelli L. Di C.; Tenci, B.; Ghelardini, C.; Angeli, A.; Supuran, C. T.; Colotta, V.; Eur. J. Med. Chem. 2018, 146, 47.

51. Yu, H.; Hou, Z.; Tian, Y.; Mou Y.; Guo C.; Eur. J. Med. Chem. 2018, $151,434$.

52. Silva, B. V.; Horta, B. A. C.; De Alencastro, R. B.; Pinto, A. C.; Quim. Nova 2009, 32, 453.

53. Ahmed, E. Y.; Latif, N. A. A.; El-Mansy, M. F.; Elserwy, W. S.; Abdelhafez, O. M.; Bioorg. Med. Chem. 2020, 28, 115328.

54. Trippier, P. C.; Jansen, L. K.; Hawker, D. D.; Mataka, J. J.; Silverman, R. B.; J. Med. Chem. 2013, 56, 3121; Barnham, K. J.; Masters, C. L.; Bush, A. I.; Nat. Rev. Drug Discovery 2004, 3, 205; Chaari, A.; Int. J. Biol. Macromol. 2019, 131, 396.

55. Luo, W.; Rodina, A.; Chiosis, G.; BMC Neuroscience 2008, 9, S7.

56. Terry, A. V. JR.; Buccafusco, J. J.; J. Pharmacol. Exp. Ther. 2003, 306, 821.

57. Ferri, C. P.; Prince, M.; Brayne, C.; Brodaty, H.; Fratiglioni, L.; Ganguli, M.; Hall, K.; Hasegawa, K.; Hendrie, H.; Huang, Y.; Jorm, A.; Mathers, C.;Menezes, P. R., Rimmer, E.; Scazufca, M.; Lancet 2005, 366, 2112; Araújo, C. R. M.; Santos, V. L. A.; Gonsalves, A. A.; Rev. Virtual Quim. 2016, 8, 1818; Viegas Junior, C.; Bolzani, V. S.; Furlan, M.; Fraga, C. A. M.; Barreiro, E. J.; Quim. Nova 2004, 27, 655.

58. Shi, D. H.; Min, W.; Song, M. Q.; Si, X. X.; Li, M. C.; Zhang, Z. Y.; Liu, Y. W.; Liu, W. W.; J. Mol. Struct. 2020, 1209,127897.
59. Najafi, Z.; Mahdavi, M.; Saeedi, M.; Karimpour-Razkenari, E.; Edraki, N.; Sharifzadeh, M.; Khanavi, M.; Akbarzadeh, T.; Bioorg. Chem. 2019, 83, 303.

60. De Souza, G. A.; Da Silva, S. J.; Del Cistia, C. D. N.; Pitasse-Santos, P.; Pires, L. D. O.; Passos, Y. M.; Cordeiro, Y.; Cardoso, C. M.; Castro, R. N.; Sant'anna, C. M. R.; Kummerle, A. E.; J. Enzyme Inhib. Med. Chem. 2019, 34, 631.

61. Mitoma, J.; Ito, A.; The Journal of Biochemistry 1992, 111, 20.

62. Fonseca, A.; Reis, J.; Silva, T.; Matos, M. J.; Bagetta, D.; Oortuso, F.; Alcaro, S.; Uriarte, E.; Borges, F.; J. Med. Chem. 2017, 60, 7206.

63. Ramsay, R, R.; Sablin, S, O.; Singer, T, P.; Prog. Brain Res. 1995, 106, 33.

64. Lan, J.; Ding, Y.; Liu, Y.; Kang, P.; Hou, J.; Zhang, X.; Xie, S.; Zhang, T.; Eur. J. Med. Chem. 2017, 139, 48.

65. Nobili, A.; Latagliata, E, C.; Viscomi, M, T.; Cavallutti, V.; Cutuli, B.; Giacovazzo, G.; Krashia, P.; Rizzo, F, R.; Marino, R.; Federici, M.; Bartolo, DE P.; Aversa, D.; Dell'acqua, M, C.; Cordella, A.; Sancandi, M.; Keller, F.; Petrosini, L.; Puglisi-Allegra, S.; Mercuri, N, B.; Coccurello, R.; Berretta, N.; D’Amelio, M.; Nat. Commun. 2017, 8, 14727.

66. Jiang, N.; Huang, Q.; Liu, J.; Liang, N.; Li, Q.; Xie, S. S.; Eur. J. Med. Chem. 2018, 146, 287.

67. Nalivaeva, N. N.; Turner, A. J.; FEBS Lett. 2013, 587, 2046.

68. Gong, Y.; Chang, L.; Viola, K. L.; Lacor, P. N.; Lambert, M. P.; Finch, C. E., Krafft, G. A.; Klein, W. L.; Proc. Natl. Acad. Sci. USA 2003, 100, 10417.

69. El-Sayed, N. F.; El-Hussieny, M.; Ewies, E. F.; Fouad, M. A.; Boulos, L. S.; Bioorg. Chem. 2020, 95, 103499.

70. Lü, J.M.; Lin, P.H.; Yao, Q.; Chen, C.; J. Cell. Mol. Med. 2010, 14, 840.

71. Traykova, M.; Kostova, I.; Int. J. Pharm. 2005, 1, 29.

72. Giles, G. I.; Jacob, C.; Biol. Chem. 2002, 383, 375; Ames, B. N.; Shigenaga, M. K.; Gold, L. S.; Environ. Health Perspect. 1993, 101, 35; Liu, R. H.; Hotchkiss, J. H.; Mutat. Res. 1995, 339, 73; Geier, D. A.; Kern, J. K.; Garver, C. R.; Adams, J. B.; Audhya, T.; Geier, M. R.; Neurochem. Res. 2009, 34, 386.

73. Matos, M.; Mura, F.; Vazquez-Rodriguez, S.; Borges, F.; Santana, L.; Uriarte, E.; Olea-Azar, C.; Molecules 2015, 20, 3290.

74. Zúñiga-Núñez, D.; Barrias, P.; Cárdenas-Jiróna, G.; Ureta-Zañartua, M. S.; Lopez-Alarcónb, C.; Vieyrac, F. E. M.; Borsarellic, C. D.; Alarcon, E. I.; Aspée, A.; RSC Adv. 2018, 8, 1927.

75. Gong, X.; Xi, G.; Liu, Z.; Tetrahedron Lett. 2015, 56, 6257.

76. Bai, Y.; Li, D.; Zhou, T.; Qin, N.; Li, Z.; Yu, Z.; Hua, H.; J. Funct. Foods 2016, 20, 453.

77. Dharavath, R.; Nagaraju, N.; Reddy, M. R.; Ashok, D.; Sarasija, M.; Vijjulatha, M.; Jyothid, V. T. K.; Prashanthid, G.; RSC Adv. 2020, 10, 11615.

78. Zavrsnik, D.; Muratovic, S.; Makuc, D.; Plavec, J.; Cetina, M.; Nagl, A.; Clercq, E. D.; Balzarini, J.; Mintas, M.; Molecules 2011, 16, 6023.

79. Gottlieb, M. S.; Schroff, R.; Schanker, H. M.; Weisman, J. D.; Fan, P. T.; Wolf, R. A.; Saxon, A. N.; N. Engl. J.Med. 1981, 305, 1425.

80. Srivastav, V. K.; Tiwari, M.; Arab. J. Chem. 2017, 10, S1081.

81. http://www.unaids.org/en, acessado em Fevereiro de 2018.

82. Kudo, E.; Taura, M.; Matsuda, K.; Shimamoto, M.; Kariya, R.; Goto, H.; Hattori, S.; Kimura, S.; Okada, S.; Bioorg. Med. Chem. Lett. 2013, 23, 606 .

83. Jesumoroti, O. J.; Faridoon; Mnkandhla, D.; Isaacs, M.; Hoppe, H. C.; Klein, R.; Med. Chem. Commun. 2019, 10, 80

84. Olomola, T. O.; Klein, R.; Lobb, K. A.; Sayed, Y.; Kaye, P. T.; Tetrahedron Lett. 2010, 51, 6325; Olomola, T. O.; Klein, R.; Mautsa, N.; Sayed, Y.; Bioorg. Med. Chem. 2013, 21, 1964.

85. Hamdy, A. M.; Khaddour, Z.; Al-Masoudi, N. A.; Rahman, Q.; HeringJunghans, C.; Villinger, A.; Langer, P.; Bioorg. Med. Chem. 2016, 24, 5115 . 
86. Barreiro, E, J.; Kümmerle, A. E.; Fraga, C. A. M.; Chem. Rev. 2011, 111 , 5215.

87. Craxi, A.; Laffi, G.; Zignego, A. L.; Mol. Aspects Med. 2008, $29,85$.

88. Hassan, M. Z.; Osman, H.; Ali, M. A.; Ahsan, M. J.; Eur. J. Med. Chem. 2016, 123, 236.

89. Hwu, J. R.; Singha, R.; Hong, S. C.; Chang, Y. H.; Das, A. R.; Vliegen, I.; Clercq, E. D.; Neyts, J.; Antiv.Res. 2008, 77, 157.

90. Hwu, J. R.; Lin, S. Y.; Tsay, S. C.; De Clercq, E.; Leyssen, P.; Neyts, J. J Med Chem. 2011, 54, 2114.

91. http://www.who.int/mediacentre/factsheets/fs211/en/, acessado em Fevereiro de 2018

92. Spanakis, N.; Pitiriga, V.; Gennimata, V.; Tsakris, A.; Expert Rev. Anti Infect. Ther. 2014, 12, 1325.

93. Palmer, R. Nature 2011, 480, S9.

94. Khomenko, T. M.; Zarubaev, V. V.; Orshanskaya, I. R.; Kadyrova, R. A.; Sannikova, V. A.; Korchagina, D. V.; Volcho, K. P.; Salakhutdinov, N. F.; Bioorg. Med. Chem. Lett. 2017, 27, 2920.

95. Wang, Y.; Yan, W.; Chen, Q.; Huang, W.; Yang, Z.; Li, X.; Wang, X.; Biomed. Pharm. 2017, 87, 583.

96. Andrade, C. H.; Kümmerle, A. E.; Guido, R. V. C.; Quím. Nova 2018, 41, 476; Parvez, A.; Meshram, J.; Tiwari, V.; Eur. J. Med. Chem. 2010, 45, 4370; Patel, D.; Kumari, P.; Patel, N. B.; Med. Chem. Res. 2013, 22 , 726; Joshi, S. D.; Manish. K.; Badiger. A.; Med. Chem. Res. 2013, 22, 869.

97. Woese, C.; Kandler, O.; Wheelis, M.; Proc. Natl. Acad. Sci. USA 1990, 87, 4576; Renuka, N.; Kumar, K. A.; Bioorg. Med. Chem. Lett. 2013, 23,6406

98. Vazquez-Rodriguez, S.; López, R. L.; Matos, M. J.; Armesto-Quintas, G.; Serra, S.; Uriarte, E.; Santana, L.; Borges, F.; Crego, A. M.; Santos, Y.; Bioorg. Med. Chem. 2015, 23, 7045.

99. Zuo, G.; Wang, C.; Han, J.; Li, Y.; Wang, G.; Phytomedicine 2016, 23 , 1814.

100. Janeczko, M.; Demchuk, O. M.; Strzelecka, D.; Kubi nski, K.; Masłyk, M.; Eur. J. Med. Chem. 2016, 124, 1019. Zhou, C.H.; Wang, Y.; Curr. Med. Chem. 2012, 19, 239.

101. López-Rojas, P.; Janeczko, M.; Kubiński, K.; Amesty, Á.; Masłyk, M.; Estévez-Braun, A. Molecules 2018, 23, 199.

102. Kumar, S.; Mukesh, K.; Harjai, K.; Singh, V.; Tetrahedron Lett. 2019 60,8 .

103. Mendonça-Junior, F. J. B.; Lima-Neto, R. G.; Oliveira, T. B.; Lima, M. C. A.; Pitta, I. R.; Galdino, S. L.; Cruz, R. M. D.; Araújo, R. S. A.; Neves, R.P.; Lat. Am. J. Pharm. 2011, 30, 1492.

104. Patil, S. A.; Prabhakara, C. T.; Halasangi, B. M.; Toragalmath, S. S.; Badami, P. S.; Spectrochim. ACTA A 2015, 137, 641.

105. Zhang, R. R.; Liu, J.; Zhang, Y.; Hou, M. Q.; Zhang, M. Z.; Zhou, F.; Zhang, W. H.; Eur. J. Med. Chem. 2016, 116, 76.

106. Blunt, J. W.; Copp, B. R.; Keyzers, R. A.; Munroa, M. H. G.; Prinsep, M. R.; Nat. Prod. Rep. 2017, 34, 235; Ahmed, A. M. M.; Taha, T. M.; Abo-Dahab, N. F.; Hassan, F. S. M.; J. Microb. Biochem. Technol. 2016 8, 256; Gao, S.; Li, X.; Williams, K.; Proksch, P.; Ji, N.; Wang, B.; J. Nat. Prod. 2016, 79, 2066.

107. Wang, J.; Huang, Y.; Fang, M.; Zhang, Y.; Zheng, Z.; Zhao, Y.; Su, W.; FEMS Immunol. Med. Microbiol. 2002, 34, 51; Bawin, T.; Seye, F.; Boukraa, S.; Zimmer, J.; Raharimalala, F. N.; Ndiaye, M.; Compere, P.; Delvigne, F.; Francis, F.; Fungal Biol. 2016, 120, 489; Zhang, C. L.; Zheng, B. Q.; Lao, J. P.; Mao, L. J.; Chen, S.Y.; Kubicek, C.P.; Lin, F.C.; Appl. Microbiol. Biotechnol. 2008, 78, 833; Losada, L.; Ajayi, O.; Frisvad, J. C.; Yu, J. J.; Nierman, W. C.; Med. Mycol. 2009, 47, S88; Liu, Y.Y.; Wang, H.; Li, F.; Molecules 2013, 18, 877.
108. Li, W.; Xiong, P.; Zheng, W.; Zhu, X.; She, Z.; Ding, W.; Li, C.; Mar. Drugs 2017, 15, 259 .

109. Yang, G.; Jin, Q.; Xu, C.; Fan, S.; Wang, C.; Xie, P.; Int. J. Biol. Macromol. 2018, 106, 179.

110. Li, K.; Dong, X.; Ma, Y.; Wu, Z.; Yan, Y.; Cheng, Y.; Fitoterapia 2019 , 134, 323.

111. Topper, Y. J.; Stetten, D., Jr.; J. Biol. Chem. 1951, 189, 191.

112. https://www.who.int/health-topics/diabetes\#tab=tab_1, acessado em Janeiro de 2020.

113. Singh, S. K.; Rai, P. K.; Jaiswal, D.; Watal, G.; Evid. Based. Complement. Alternat. Med. 2008, 5, 415.

114. Lebovitz, H.; Clin. Diabetes 1995, 13, 99.

115. Singha, P.; Ngcoyaa, N.; Mopurib, R.; Kerrua, N.; Manhasa, N.; Ebenezera, O.; Islamb, S.; Lett. Drug. Des. Discov. 2018, 15, 127.

116. Goldstein, J. B.; Curr Drug Targets Immune Endocr. Metabol. Disord. 2001, 1, 265.

117. Jung, H. J.; Seong, S. H.; Ali, M. Y.; Min, B. S.; Jung, H. A.; Choi, J. S.; Arch. Pharm. Res. 2017, 40, 1403.

118. Li, J. L.; Gao, L. X.; Meng, F. W.; Tang, C. L.; Zhang, R. J.; Li, J. Y.; Luo, C.; Li, J.; Zhao, W. M.; Bio. Med. Chem. Lett. 2015, 25, 2028.

119. Jurgens, C. A.; Toukatly, M. N.; Fligner, C. L.; Udayasankar, J.; Subramanian, S. L.; Zraika, S.; Aston-Mourney, K.; Carr, D. B.; Westermark, P.; Westermark, G. T.; Kahn, S. E.; Hull, R. L.; Am. J. Pathol. 2011, 178, 2632.

120. Vinayagam, R.; Xu, B.; Phytomedical. 2017, 24, 119.

121. Daniele, G.; GuardadoMendoza, R.; Winnier, D.; Fiorentino, T.V.; Pengou, Z.; Cornell, J.; Andreozzi, F.; Jenkinson, C.; Cersosimo, E.; Federici, M.; Tripathy, D.; Folli, F.; Acta Diabetol. 2014, 51, 123.

122. Choi, R. Y.; Bio. Med. Chem. Lett. 2016, 26, 4655.

123. Bansal, Y.; Sethi, P.; Bansal, G.; Med. Chem. Res. 2013, 22, 3049; Medzhitov, R.; Cell 2011, 140, 771.

124. Cruz-Machado, S. S.; Revista da Biologia 2010, 4, 40.

125. Mu, C.; Wu, M.; Li, Z.; Chem. Biodiversity 2019, 16, e1800559.

126. Chen, L. Z.; Sun, W. W.; Bo, L.; Wang, J. Q.; Xiu, C.; Tang, W. J.; Shi, J. B.; Zhou, H. P.; Liu, X. H.; Eur. J. Med. Chem. 2017, 138, 170.

127. Vitale, P.; Tacconelli, S.; Perrone, M. G.; Malerba, P.; Simone, L.; Scilimati, A.; Lavecchia, A.; Dovizio, M.; Marcantoni, E.; Bruno, A.; J. Med. Chem. 2013, 56, 4277; Perrone, M.G.; Scilimati, A.; Simone, L.; Vitale, P.; Curr. Med. Chem. 2010, 17, 3769.

128. Masferrer, J. L.; Zweifel, B. S.; Manning, P. T.; Proc. Natl. Acad. Sci. USA 1994, 91, 3228.

129. FitzGerald, G. A.; Patrono, C. N.; N. Engl. J. Med. 2001, 345, 433.

130. Grover, J.; Kumar, V.; Sobhia, M. E; Jachak, S. M.; Bioorg. Med. Chem. Lett. 2014, 24, 4638.

131. Cronstein, B. N.; Weissmann, G. Annu. Rev. Pharmacol. Toxicol. 1995, $35,449$.

132. Motai, T.; Kitanaka, S.; Chem. Pharm. Bull. 2004, 52, 1215.

133. Winrow, V. R.; Winyard, P. G.; Morris, C. G.; Blake, D. R.; Br. Med. Bull. 1993, 49, 506.

134. Lv, H. N.; Wang, S.; Zeng, K. W.; Li, J.; Guo, X.Y.; Ferreira, D.; Zjawiony, J.K.; Tu, P.F.; Jiang, Y.; J. Nat. Prod. 2015, 78, 279-285.

135. Liu, Y.-P.; Yan, G.; Xiea, Y-T.; Lina, T-C; Zhanga, W.; Lia, J.; Wua, Y-J.; Zhoua, J-Y.; Fu, Y-H.; Bioorg. Chem. 2020, 97, 103699.

136. Srivastava, P.; Vyas, V.K.; Variya, B.; Patel, P.; Qureshi, G.; Ghate, M.; Bioorg. Chem. 2016, 67, 130. 